\title{
Analyzing chemical changes in verdigris pictorial specimens upon bacteria and fungi biodeterioration using voltammetry of microparticles
}

\author{
Annette S. Ortiz-Miranda ${ }^{1}$, Antonio Doménech-Carbó ${ }^{*}$, María Teresa Doménech-Carbó ${ }^{1}$, Laura Osete-Cortina ${ }^{\text {, }}$ \\ Fernando Bolívar-Galiano ${ }^{3}$ and Inés Martín-Sánchez ${ }^{4}$
}

\begin{abstract}
It is reported the application of the voltammetry of microparticles (VMP), complemented with attenuated total reflectance Fourier transform infrared spectroscopy (ATR-FTIR) and field emission scanning electron microscopy (FESEM) techniques, to monitor the deterioration of verdigris pictorial specimens under the action of different biological agents. This methodology would be of application for identifying the type of biological agent causing deterioration of paintings, which is an important problem affecting cultural heritage. The analysis of biodeterioration processes is complicated by the fact that the action of microorganisms can affect both pigment and binding media. The deterioration of pictorial specimens combining verdigris with egg and egg-linseed oil binders by Penicillium chrysogenum, Aspergillus niger, Acremonium chrysogenum, Trychoderma pseudokoningi and Mucor rouxii fungi and Bacillus amyloliquefaciens, Arthrobacter oxydans and Streptomyces cellulofans bacteria were tested using sample-modified graphite electrodes immersed into aqueous electrolytes. A model is presented to describe the involved electrochemistry resulting in specific voltammetric features for the electrochemical reduction of verdigris associated to the proteinaceous and lipidic fractions of the binders. The experimental results and model proposed have been discussed and compared with those previously obtained for cadmium yellow reconstructed paint film specimens.
\end{abstract}

Keywords: Electrochemistry, Biodeterioration, Verdigris, Cadmium sulfide, Egg tempera, Egg-oil emulsion

\section{Background}

The growth of microorganisms is one of the major concerns in all museums worldwide due to the aesthetical and structural damage that it may cause. Artistic paintings are constituted of a wide range of organic and inorganic materials; most of these components are biodegradable. The analysis of biodeterioration processes affecting pictorial works of art is complicated by the fact that the action of microorganisms can affect both pigments and binding media. Since to nowadays, art treatises have detailed descriptions of these materials that

\footnotetext{
*Correspondence: antonio.domenech@uv.es

2 Departament de Química Analítica, Universitat de València, Dr. Moliner,

50, Burjassot, 46100 Valencia, Spain

Full list of author information is available at the end of the article
}

many microorganisms may utilize for growth such as polysaccharides, proteins, oils, waxes, etc. $[1,2]$.

In this context, the study of biodeterioration of pigment-containing paint films is of interest because of the changes induced in the visual appearance of the painting, but also by its effect in its long-term preservation due to the loss of chemical and mechanical stability [3]. In fact, pigments can act as inhibitors or catalysts in the drying of oils $[2,4,5]$, whereas fatty acids released from hydrolysis of triglycerides can form metal soaps with metal ions from some pigments [6-11] which can migrate through the semi-permeable paint system to the paint surface where they are mineralized and aggregate forming protrusions $[7,8]$.

In presence of microorganisms, plant gums, proteinaceous media and drying oils mainly undergo hydrolysis, 
which often is followed by oxidation processes. Additionally, crosslinking, condensation, and dehydration of amino acids can take place as consequence of microbial action or environmental agents [12]. Environmental deterioration of oil paint films can be also due to crosslinking reactions, oxidation of unsaturated acids and hydrolysis of glyceride bonds releasing free fatty acids, which can complex pigments forming metal soaps [6]. These processes can be accompanied by changes in the chemical composition and morphology of the pigments that can act as catalysts or react with the byproducts that result from the biodeterioration of the organic binders.

Although organic supports of paintings such as panels or canvas are more sensitive to the microbial colonization, paint layers composed of proteinaceous or polysaccharide binding media can be also the target of a variety of microorganisms. In particular, growing of microorganisms in paint layers in which verdigris was used has been observed in ancient pictorial artworks such as the Cinctorres Altarpiece (anonymous, fourteenth century, Cinctorres, Spain). Examination by FESEM enabled the identification of fungus spores located on the crack and pores formed in the surface of the painting. A number of based electron microscopy, spectroscopic and chromatographic techniques enable the study of the changes undergone by the binders under biological attack; however, the study of the minimal modifications often occurring in the pigment are difficult and analytical techniques highly selective and sensitive are required. Voltammetry of microparticles (VMP), a solid state electrochemistry technique developed by Scholz et al. [13] is highly sensitive to the electrochemical response of graphite electrodes modified with microparticulated samples of paint. Voltammetric profiles are not only sensitive to the pigment but also to other materials present in the sample, binding media in particular. Among a variety of materials $[14,15]$, this technique has been extensively applied in the field of conservation and restoration, as recently reviewed [16, 17]. In a previous report [18], we described the application of this methodology to characterize the biological attack of different species of bacteria and fungi to reconstructed egg tempera and egg-linseed oil emulsion paint films containing cadmium yellow (CdS). In the current report, we present a voltammetric study on the biological attack of a set of bacteria and fungi species to reconstructed paint films containing verdigris as a pigment aimed to assess the possibility of determining specific responses for the different types of biodegradation. The simplicity and versatility of the technique makes it potentially interesting for the study of biodeterioration of paintings. The pigment verdigris is particularly interesting because of (i) its frequent use in painting until the 19th [19] and (ii) its anti-fungal properties [20].
The voltammetric response of verdigris, which was previously used for identification purposes [21], was studied here in a series of reconstructed egg tempera and egg-linseed oil emulsion paint films submitted to biological attack with different fungi (Acremonium chrysogenum, Aspergillus niger, Mucor roxii, Penicillium chrysogenum, and Trichoderma pseudokoningii) and bacteria (Arthrobacter oxydans, Bacillus amyloliquefaciens, and Streptomyces cellulofans) typically involved in paint deterioration [22-30] and compared with the response of CdS-based films. Voltammetric data have been complemented with attenuated total reflectanceFourier transform infrared spectroscopy (ATR-FTIR) in order to gain information on the modification of chemical bonds of the binder upon biological attack and the formation of copper complexes. Field emission scanning electron microscopy (FESEM) was used for the examination of the prepared specimens. This technique, which provides enhanced resolution relative to conventional electron microscopy, was devoted to investigate the morphological changes occurred in the films during the biodeterioration.

\section{Experimental}

\section{Instrumentation}

Electrochemical experiments were performed at $298 \mathrm{~K}$ in a three-electrode cell under argon atmosphere using a $\mathrm{CH}$ I660C device (Cambria Scientific, Llwynhendy, Llanelli UK). A platinum wire counter-electrode and an $\mathrm{Ag} / \mathrm{AgCl}(3 \mathrm{M} \mathrm{NaCl})$ reference electrode completed the three-electrode arrangement.

$0.25 \mathrm{M}$ sodium acetate buffer (Panreac) at $\mathrm{pH} 4.75$ was used as a supporting electrolyte. Cyclic voltammograms (CVs) were obtained using abrasive VMP protocols. Importantly, the electrolyte solution was renewed after each electrochemical run to avoid contamination due to cadmium ions eventually released to the solution phase during electrochemical turnovers. Commercial paraffin-impregnated graphite bars of (Staedtler 200 HB type, $68 \%$ wt graphite, diameter $2 \mathrm{~mm}$ ) were used. Prior to the series of runs for each material or sample, a conditioning protocol was used to increase repeatability. The electrode surface was polished with alumina, rinsed with water and polished by pressing over paper. For electrode modification, an amount of 1-2 mg of the sample was extended on an agate mortar forming a spot of finely distributed material. Then the lower end of the graphite electrode was gently rubbed over that spot of sample and finally rinsed with water to remove illadhered particles. Sample-modified graphite bars were then dipped into the electrochemical cell so that only the lower end of the electrode was in contact with the electrolyte solution. This procedure provides an almost 
constant electrode area and reproducible background currents.

The IR spectra in the ATR mode of the powdered samples were obtained using a Vertex 70 Fourier-transform infrared spectrometer with an FR-DTGS (fast recovery deuterated triglycine sulphate) temperature-stabilised coated detector and a MKII Golden Gate Attenuated Total Reflectance (ATR) accessory. A total of 32 scans were collected at a resolution of $4 \mathrm{~cm}^{-1}$ and the spectra were processed using the OPUS/IR software.

Field emission scanning electron microscopy (FSEM). Secondary electron images were obtained using a Zeiss model ULTRA 55 operating with a Oxford-X Max X-ray microanalysis system controlled by Inca software. The analytical conditions were: $1 \mathrm{kV}$ accelerating voltage. Samples were directly observed in order to avoid interference with the particulate structure of the coating element used for eliminating charging effects.

\section{Reference materials and test specimens}

Cold pressed linseed oil, verdigris [synthetic copper(II) acetate, Kremer] and fresh hen's egg were used as reference materials for preparing the series of paint films. Reconstructed egg tempera paint films (EG) were prepared by mixing the pigment with the appropriate amount of egg until suitable consistence (30\% weight composition of pigment); and spreading this product on glass slides in order to form a thin film. The paint films were dried at room temperature during 4 weeks $\left(21{ }^{\circ} \mathrm{C}, 50 \% \mathrm{RH}\right)$. Thickness of the films was in the range $0.3-0.5 \mathrm{~mm}$. Reconstructed egg-linseed oil emulsion paint films (EO) were prepared by mixing the pigment with the appropriate amount of an egg-linseed oil emulsion (1:1) (35\% weight composition of pigment). The reconstructed paint films were dried at room temperature during 4 weeks $\left(21^{\circ} \mathrm{C}, 50 \% \mathrm{RH}\right)$. Thickness of the films was in the range $0.3-0.5 \mathrm{~mm}$.

\section{Microorganisms and cultures}

Bacterial and fungal strains, obtained from the Spanish Collection of Type Cultures (CECT, Colección Española de Cultivos Tipo, Universidad de Valencia, Valencia, Spain), were chosen because they have been frequently found in biodeterioration studies of cultural heritage [22-30]. The selected fungi were: Acremonium chrysogenum (Ac) (CECT 2718, ATCC 14615), Aspergillus niger (An) (CECT 2088, ATCC 9029), Mucor rouxii (Mr) (CECT 2655, ATCC 24905), Penicillium chrysogenum (Pc) (CECT 2306, ATCC 8537) and Trychoderma pseudokoningii (Tp) (CECT 2937). The selected bacteria were: Arthrobacter oxydans (Ao) (CECT 386, ATCC 14358), Bacillus amyloliquefaciens (Ba) (CECT 493, ATCC 23842) and Streptomyces cellulofans (Sc) (CECT 3242, ATCC 29806).
Bacteria were grown on culture plates of Trypticase Soy Agar (TSA, Scharlau) medium and were incubated at $28{ }^{\circ} \mathrm{C}$ for $24 \mathrm{~h}$. Cultures were re-suspended in $2 \mathrm{~mL}$ of $0.1 \%$ Tween 80 solution (Aldrich). After centrifugation carried out for removing possible remains of the solid culture medium, bacterial suspensions were adjusted to $10^{7}$ cells $\mathrm{mL}^{-1}$. To obtain fungal spores, fungi were grown on Potato Dextrose Agar (PDA, Scharlau, Barcelona, Spain) over a total period of 1 week at $28{ }^{\circ} \mathrm{C}$ and spores were collected by washing the solid culture with $0.1 \%$. Tween 80 solution and filtering through sterile glass wool. The resulting suspensions of spores were centrifuged three times and the supernatants were discarded in order to avoid any residue from the culture medium or rest of mycelia. Finally, spores were re-suspended in $1 \mathrm{~mL}$ ultrapure water and spores suspensions were adjusted to $10^{5}-10^{6}$ spores $\mathrm{mL}^{-1}$.

\section{Inoculation and incubation of paint specimens}

Reconstructed paint films prepared as egg yolk tempera (EG) and egg-oil emulsion (EO) were inoculated with three separated drops of $20 \mu \mathrm{L}$ of each fungal and bacterial suspension. After inoculation, each paint film was placed in the center of a Petri dish and incubated in darkness for 40 days at $28{ }^{\circ} \mathrm{C}, 80 \%$ relative humidity. Thus, two series of biodeteriorated reconstructed paint films were obtained (EG@microorganism and EO@microorganism). Paint films inoculated with $20 \mu \mathrm{L}$ of sterile ultrapure water and incubated under the same conditions were used as controls (EG@BLANK and EO@BLANK). After incubation, the microbial biomass was completely separated from the surface of the reconstructed paint films in two steps, (1) mechanical removing mycellums, spores, etc. by carefully rolling a sterile cotton-swab on the biodeteriorated area. Eventually, sterile microscalpel was used for removing some small craquelure detached of the paint film as consequence of the microbial action (see Fig. 1). (2) Rinsing with sterile water for removing the biomass that still could remain.

\section{Results and discussion FESEM examination}

Figure 1 shows the visual appearance of the surface of the uninoculated egg tempera paint film EG@BLANK (Fig. 1a) and the EG@Ac specimen after inoculationincubation and partial removing of the biomass (Fig. 1b). It can be seen that abundant spores of Acremonium chrysogenum are still covering the surface of the paint film. Figure 1c and d show the surface of the EG@Sc and EG@ Mr specimens, respectively, after inoculation-incubation and complete suppression of the biomass. It can be seen that a network of craquelures has been formed as result of the inoculation. Similarly, the visual appearance of the 

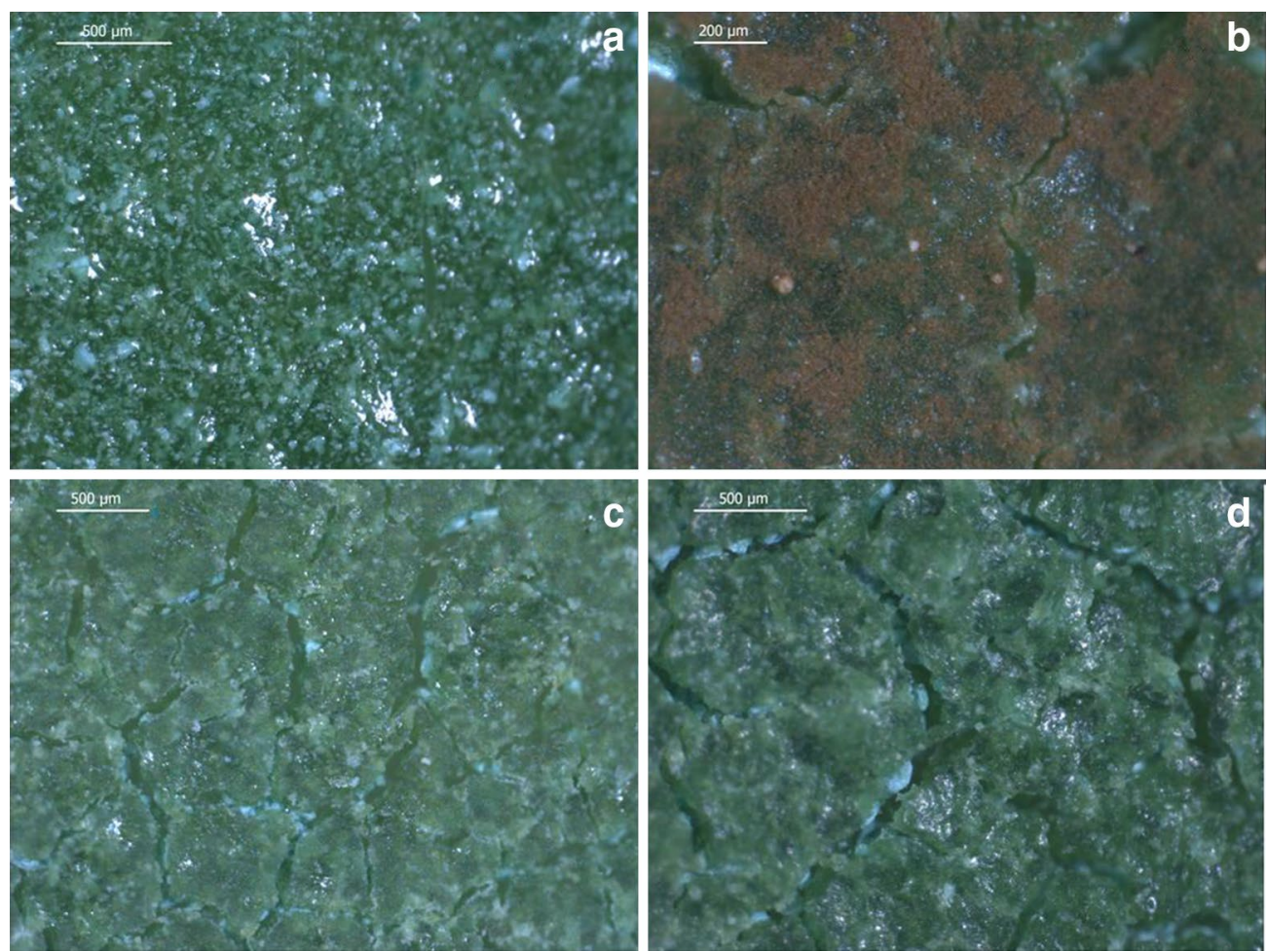

Fig. 1 Photograph of the surface of the reconstructed egg-tempera paint film specimens: a EG@BLANK, $\mathbf{b} E G @ A c$ after inoculation-incubation and cEG@Sc, dEG@Mr after inoculation-incubation and suppression of the biomass

reconstructed egg-oil emulsion paint films can be seen in Fig. 2. Spores of Trychoderma pseudokoningii are also covering the surface of the paint film but at lesser extent than in the egg tempera specimens (Fig. 2b). Growing of Bacillus amyloliquefaciens bacterium has resulted in a loss of the characteristic gloss of this type of films conferred by the oil (Fig. 2d).

Figure 3a shows the electron secondary image of the EG@BLANK un-inoculated specimen. The surface of the paint film is flat, eventually disrupted by small pores (asterisk) produced during the drying of the film and abundantly protruded by small spherical features (arrow) that are associated with dense protein-lipid particles (less than $4 \mu \mathrm{m}$ diameter) characteristic of egg yolk. Some changes in the surface morphology are observed in the EG@Tp specimen inoculated with Trychoderma pseudokoningii that illustrate the effect of fungi growing in the paint film (Fig. 3b). It can be seen that the surface of the film is microeroded (arrow) as consequence of the microbial attack, which has altered the substrate. Microcrystals of nanometric size are spread on the surface of the film and form irregular aggregates around the spores of the fungus (asterisk). They are supposed to be formed by rests of the binding medium altered by the fungus. A different aspect exhibits the surface of the
EG@Ba specimen inoculated with Bacillus amyloliquefaciens eubacterium that is shown in Fig. 3c. As it can be seen in the image, the microbial attack has resulted in the formation of microcracks (arrow) along which the grains of pigment are partially emerging. Microorganisms, in general, seem to be specially active on the consumption of proteins as shown in Fig. 4 in which it can be seen the aspect of a dense protein-lipid particle (arrow) after the bacterium attack. These particles consisted of a nucleus (a) mainly composed of triacylglycerols covered by a spherical layer of proteins (b). This structure is stabilized by phospholipids that are also located in the internal side of this external layer. In the image can be seen that part of this protein and phospholipid-rich external layer has been lost by the bacteria, whose features are still visible attached to the granule (c).

The egg-oil emulsion specimens showed, in general, a more irregular surface than that of the egg tempera paint films as can be seen in Fig. 5a. A number of cracks (arrow) are formed as consequence of the stretching forces that take place on the paint as consequence of the dehydration-oxidation-polymerization processes associated to the drying of the film. The combined action of these processes results in the macroscopical shrinkage of the film. The image also shows a sphere from the yolk 


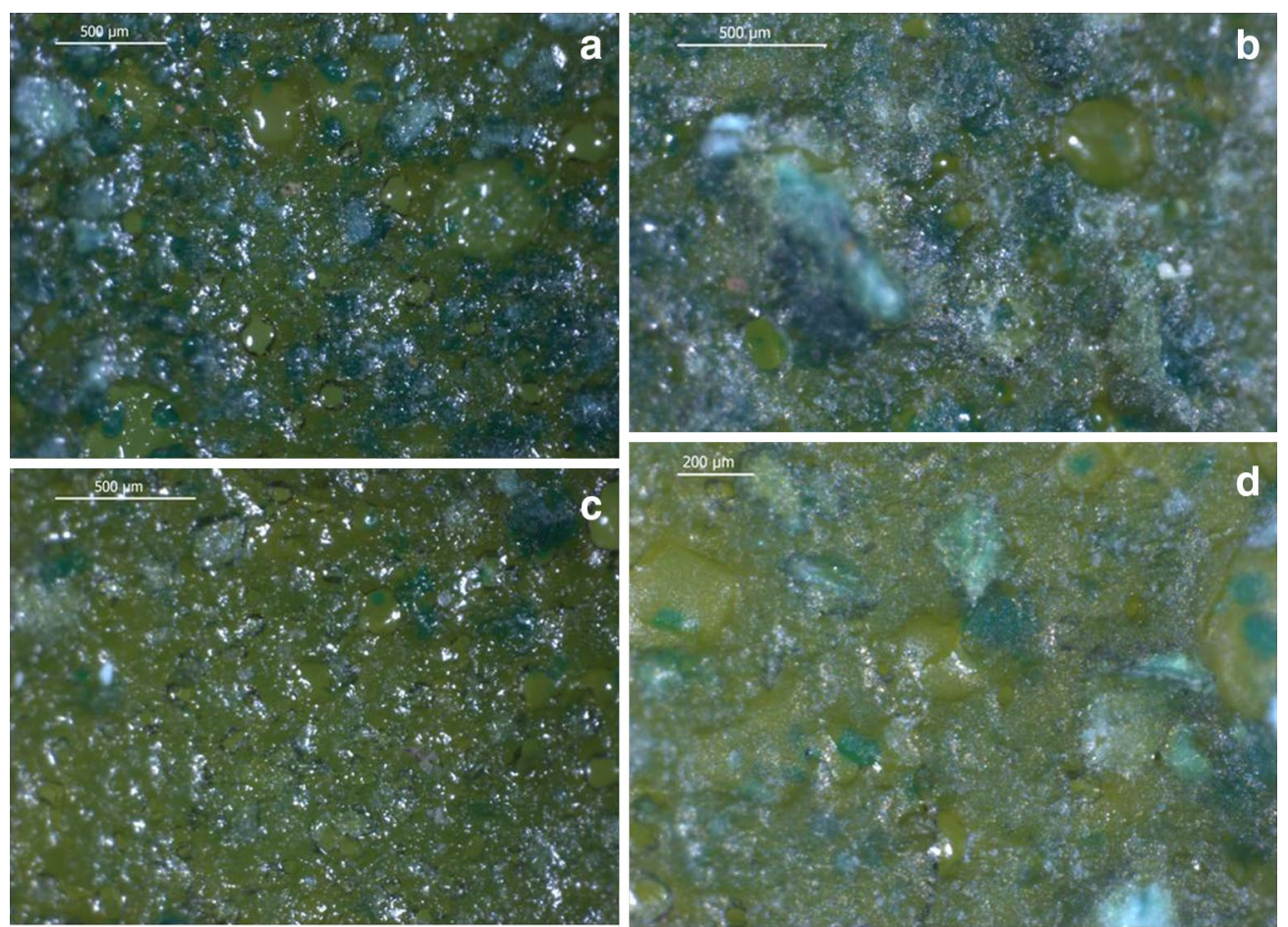

Fig. 2 Photograph of the surface of the reconstructed egg-tempera paint film specimens: a EO@BLANK, b EO@Tp after inoculation-incubation, c EO@Pc after inoculation-incubation and suppression of the biomass, $\mathbf{d}$ EO@Ba after inoculation-incubation and suppression of the biomass

(asterisk) and microcrystals mainly associated to copper soaps but also to copper-protein complexes formed as result of the interaction between the pigment and the binding medium (upper arrow). Apart from the increase of microcracks and irregular aggregates of microcrystals (lower arrow), similar micromorphology to the uninoculated paint film, with abundant aggregates of microcrystals is observed in the specimen EO@An inoculated with the fungus Aspergillus niger, which is shown Fig. 5b. Finally, Fig. $5 \mathrm{c}$ shows the aspect of the surface of the paint film EO@Ao inoculated with Arthrobacter oxydans bacterium. Activity of this microorganism has also promoted the formation of copper complexes in this paint film (arrow).

\section{FTIR spectroscopy \\ Uninoculated specimens}

This analytical technique has enabled the monitoring of the changes undergone by the two studied binders as consequence of the action of microorganisms tested. IR spectra of the EG and EO series of reconstructed paint films have been performed for obtaining complementary information to that provided by solid state electrochemistry technique. Figure 6 shows the IR spectra obtained in egg, EG@BLANK and EO@BLANK specimens. These spectra are dominated by bands characteristic of stretching vibrations of amide A and methyl/methylene, carbonyl and amide I groups in egg proteins together with stretching vibrations of hydroxyl and $\mathrm{Cu}$-carboxylate groups in neutral verdigris in the two last spectra. Of particular interest are the differences observed in the $1800-1500 \mathrm{~cm}^{-1}$ region. Thus, intensity of amide I band in EG@BLANK is significantly lower than that for pure egg. This band is associated with the stretching vibrations of $\mathrm{C}=\mathrm{O}(70-85 \%)$ and $\mathrm{C}-\mathrm{N}$ groups $(10-20 \%)$ and the position of this band is directly related to the backbone conformation of the polypeptide chains and the hydrogen bonding pattern. Therefore, the decrease of the intensity of this band in the IR spectra of both pigment-containing specimens can be related to a breakdown of the protein chains according to prior studies devoted to the effect of verdigris in egg tempera medium [31]. On the other hand, maximum of the amide I band appears slightly redshifted from 1633 to $1628 \mathrm{~cm}^{-1}$ in EG@BLANK evidencing changes in the $\beta$-sheet conformation of the proteins as consequence of the presence of pigment. Aggregated intermolecular $\beta$-sheets, rigid $\beta$-hairpin with specific turns structures or $\beta$-structures less accessible to the external medium or intermolecular contacts between extended chain segments are conformations ascribed to this $1610-1630 \mathrm{~cm}^{-1}$ lower range [32]. Secondary maximum exhibited by the amide I band at $1651 \mathrm{~cm}^{-1}$ in the 


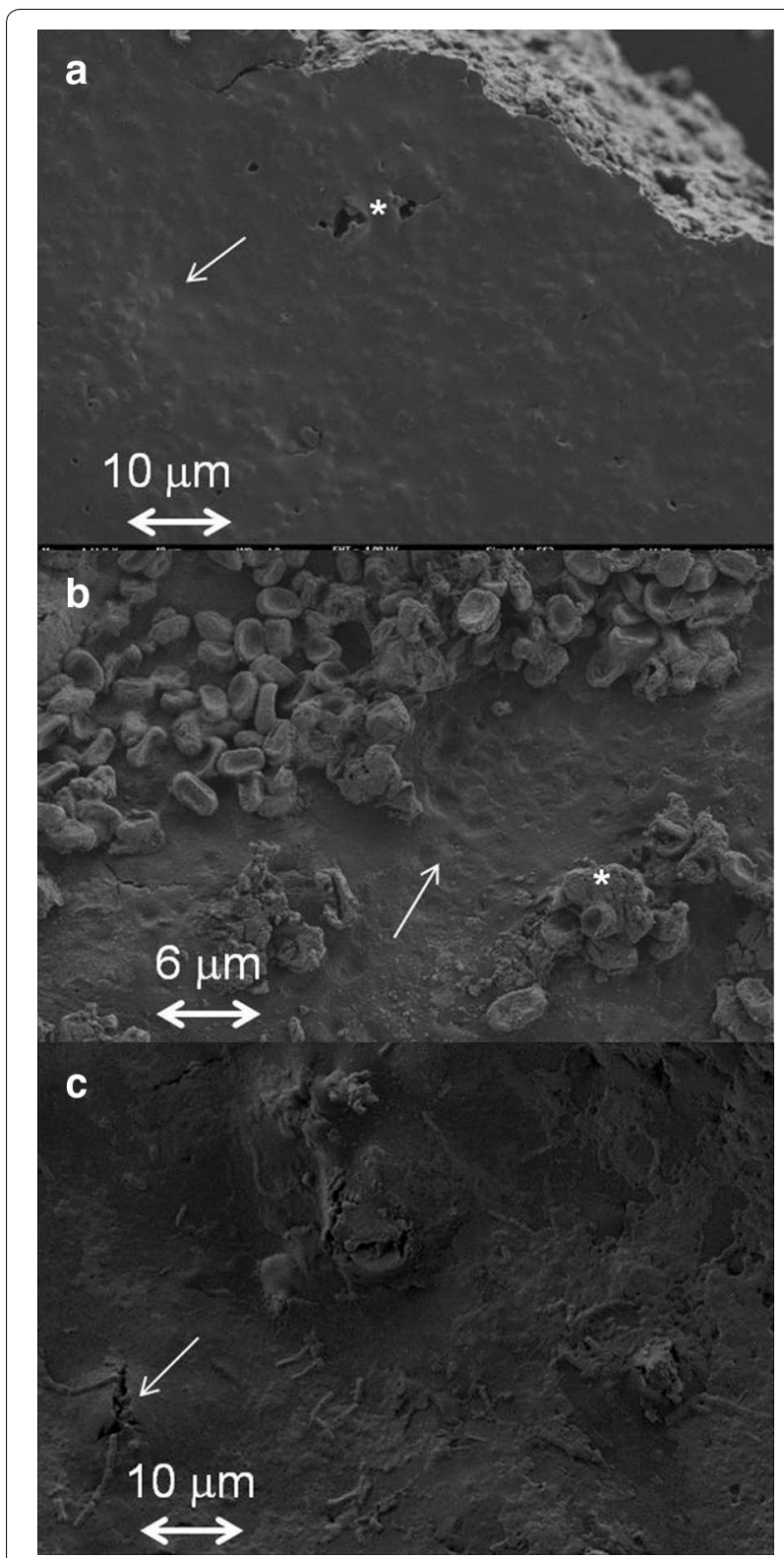

Fig.3 Secondary electron image obtained in: a EG@BLANK, showing pores (asterisk) and protrusions (arrow); b EG@Tp showing an aggregate around fungal spore (asterisk) and microerosins (arrow); c EG@Ba, showing microcracks (arrow)

pure egg specimen occurs at lower spatial frequencies of 1646 and $1650 \mathrm{~cm}^{-1}$ in EG@BLANK and EO@BLANK specimens. This sub-band in the amide I region has been associated with $\alpha$-helix conformations and the downshifting of its position can be related to the increase of the helix length and its bending in coiled coils but also to the increase of the exposition of the helix to the external medium (aqueous plasma and pigment) [32]. The shorter redshift observed in the EO@BLANK for this sub-band suggests that the presence of drying oil reduces the interaction between the protein and the pigment.

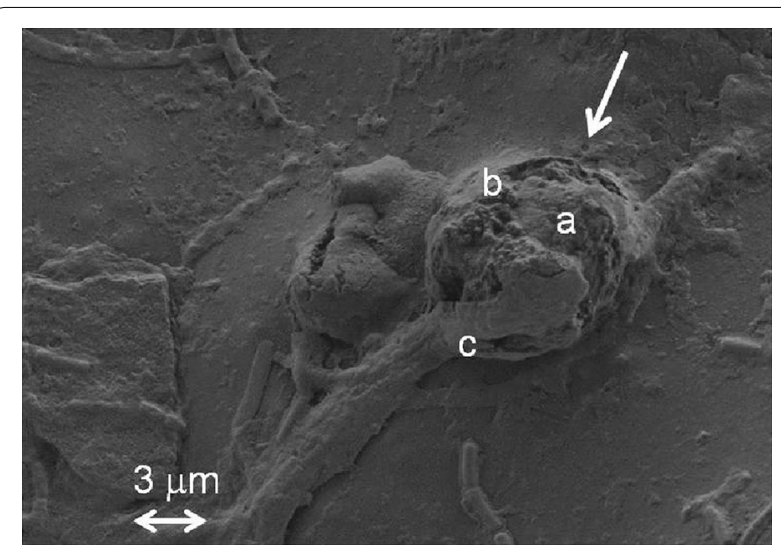

Fig. 4 Secondary electron image of sample EG@Ba. Detail of the alteration of a denser protein-lipid particle due to the selective action of the bacterium

The amide II band is found in the $1480-1580 \mathrm{~cm}^{-1}$ region and derives mainly from in-plane $\mathrm{N}-\mathrm{H}$ bending accompanied of $\mathrm{C}-\mathrm{N}$ and $\mathrm{C}-\mathrm{C}$ stretching vibrations [33]. A notable increase in the intensity of this band is observed in the IR spectra of both specimens containing pigment if they are compared with that of pure egg. Maximum at $1531 \mathrm{~cm}^{-1}$ ( $\beta$-sheet conformations) is blueshifted to 1543 and $1552 \mathrm{~cm}^{-1}$ (helical conformations) [34] in EG@BLANK and EO@BLANK, respectively. In addition, shoulders at 1557, 1572 and $1585 \mathrm{~cm}^{-1}$ are also identified in their second derivative spectra. These features can be directly correlated with the interaction of the pigment with both the lipid and proteinaceous components of the binders. Shoulder at $1585 \mathrm{~cm}^{-1}$ has been related to the formation of complexes of $\mathrm{Cu}(\mathrm{II})$ with free fatty acids released from triacylglycerols and phospholipids in linseed oil and egg yolk [6, 10]. Asymmetric stretching vibration due to the coordination of the carboxylic residues (glutamic and aspartic acid) in the protein molecules with divalent ions, according with data reported in literature, also occurs in the range 1590$1551 \mathrm{~cm}^{-1}[35,36]$. In addition, several studies are found in literature concerning the compounds that can be formed between copper ions and proteinaceous materials in which is described the ability of copper ions for coordinating with the carboxylic groups present in the side chains of the protein macromolecules thus facilitating the decarboxylation of proteins $[37,38]$ and the release of glutamic and aspartic acid [39].

A notable decrease in the shoulder appearing in the range $1700-1720 \mathrm{~cm}^{-1}$ in the egg specimen is observed in both EG@BLANK and EO@BLANK specimens. This band is ascribed to the stretching vibrations of the carboxylic groups from free fatty acids that should be released from the lipids and phospholipids of egg and linseed oil as result of hydrolysis processes. The reduction in the 

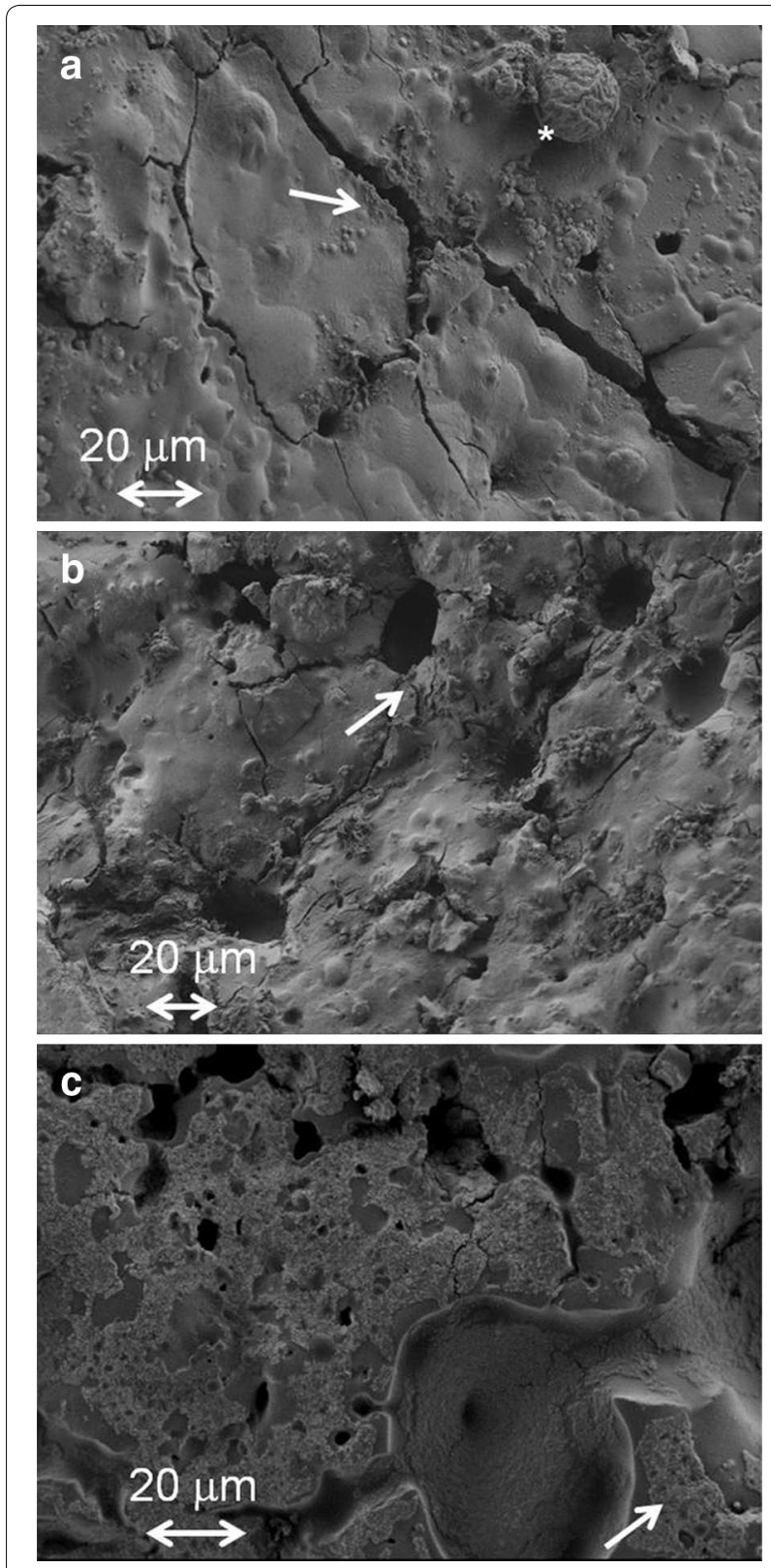

Fig. 5 Secondary electron image obtained in: a EO@BLANK showing cracks (arrow) and a microsphaeroidal feature (asterisk), b EO@An showing pores and aggregates of microcrystals (arrow); c EO@Ao showing irregular features presumed to be associated to the formation of copper complexes (arrow)

intensity of this IR band can be directly correlated with the increase in the intensity of the IR band associated with the copper-protein complexes and copper soaps.

\section{Inoculated specimens}

As a prior step, presence of unremoved rests of biological materials (fungi or bacteria biomass consisting of spores, endospores, vegetative or degraded cell walls, mycelia, conidia etc.), which could interfere the identification of alteration processes occurring in the binding media or verdigris pigment was checked from the IR spectra obtained from samples excised in the inoculated paint specimens. According to literature [40, 41], IR spectra obtained in pure fungal materials in the high spatial frequency region are dominated by bands originated from the stretching vibrations of $-\mathrm{OH}$ and $-\mathrm{NH}$ groups of proteins and the stretching vibrations of methyl and methylene groups of lipids. In the fingerprint region $\left(1800-500 \mathrm{~cm}^{-1}\right)$ the IR spectra are dominated by the strong carbohydrate band at $1064 \mathrm{~cm}^{-1}$ and the amide I and amide II bands at ca. $1635-38$ and $1540-46 \mathrm{~cm}^{-1}$, respectively. Moderate band at $1450 \mathrm{~cm}^{-1}$ ascribed to the to asymmetric bending of $\mathrm{CH}_{3}$ groups in proteins is also observed together with moderate-weak bands at 1237 and $1082 \mathrm{~cm}^{-1}$ associated with stretching vibrations of $\mathrm{PO}_{2}^{-}$group of phospholipids [42]. Characteristic band at $1600 \mathrm{~cm}^{-1}$ is sometimes recognized, which is associated with low-molecular-weight organic compounds due to fungal metabolites and decomposition of cell walls of dead fungi [41]. Occurrence of these same IR bands ascribed to proteins, lipids and phospholipids in egg hinders the use of the above mentioned IR bands for identifying rests of biological material on the paint films. Nevertheless, strong band at $1064 \mathrm{~cm}^{-1}$ from carbohydrates is a satisfactory marker able to be used to detect the presence of rest of fungal biomass deposited on the surface of the paint films. Analogous situation takes place with bacteria, which exhibit IR spectra dominated by bands of polysaccharides, proteins, lipids and phospholipids. However, characteristic features at 1456 and $783 \mathrm{~cm}^{-1}$ of bacterial endospores associated to the pyridine-2,6-dicarboxylic [dipicolinic acid (DPA)] can be used for identifying the presence of rests of bacterial materials together with the polysaccharide bands [42, 43].

Figure $7 \mathrm{a}$ shows a detail of the $1800-500 \mathrm{~cm}^{-1}$ region in the IR spectra of egg tempera paint film specimens EG@BLANK, EG@Pc and EG@Ao. The position of the characteristic bands of marker compounds of bacterial and fungal materials has been superimposed to denote the absence of these compounds in the specimens. Similarly, Fig. 7b shows in detail the IR spectra of egg-oil emulsion paint films EO@BLANK, EO@Ac, and EO@Sc. The absence of biological material on the surface of the egg-oil emulsion paint films is again confirmed.

The effect of microorganisms on the paint films has resulted, in general, in slight changes in the previously described IR bands for egg tempera and egg-oil emulsion media. The more remarkable changes have been observed in the $1800-1500 \mathrm{~cm}^{-1}$ region. Notably, Acremonium chrysogenum fungus presented the highest 


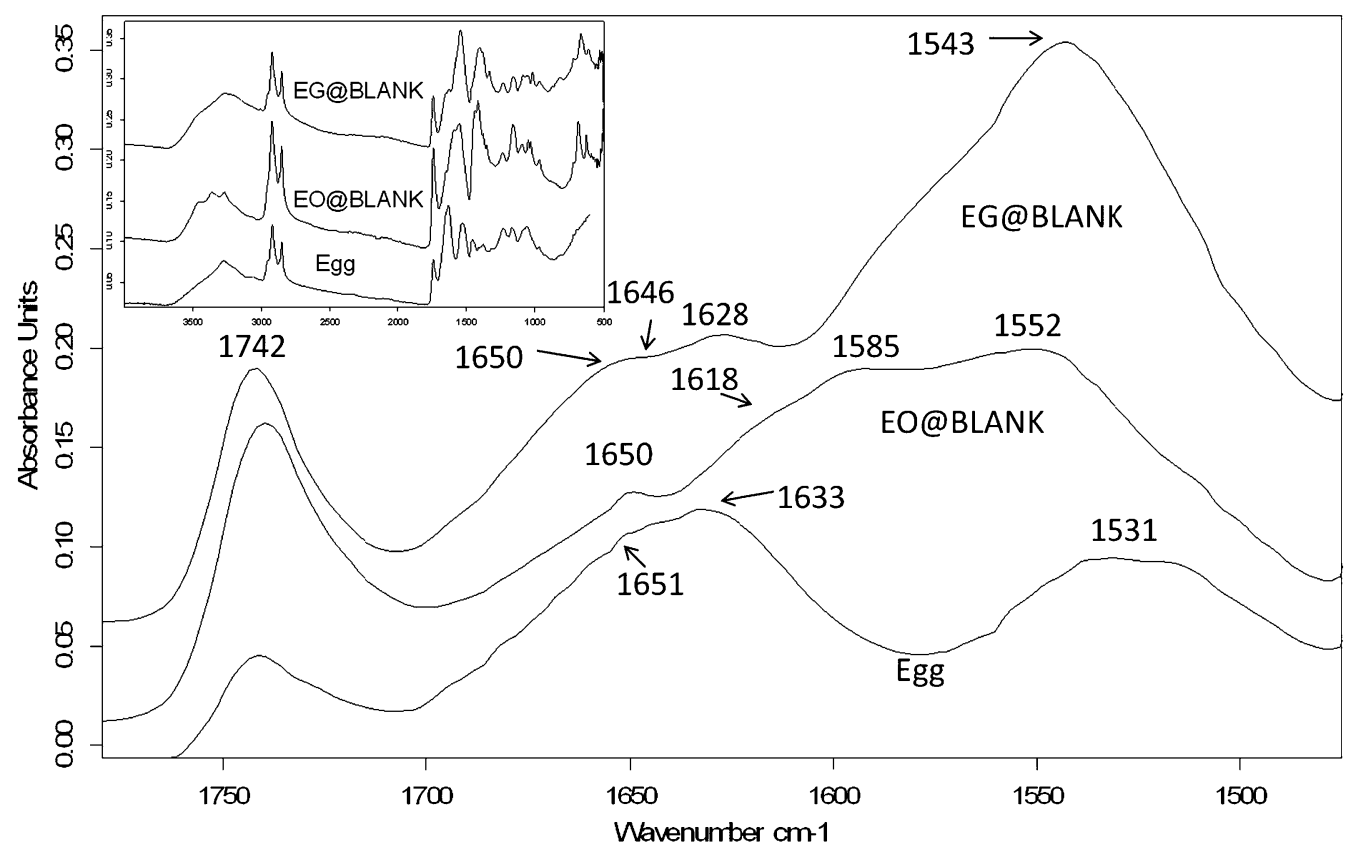

Fig. 6 IR spectra of pure egg and paint film specimens EG@BLANK and EO@BLANK

value for the amide I/amide II intensity ratio among the specimens inoculated with fungus (see EG@Ac spectrum shown in Fig. 8a) with a prominent maximum of the amide I band at $1628 \mathrm{~cm}^{-1}$ that evidences that $\beta$-sheet is the prevalent conformation in this medium. Dominance of this structure, in which lateral chains are less accessible to the external medium, is in good correspondence with the scarce formation of $\mathrm{Cu}$-carboxylate complexes (absence of shoulder in the amide II band at $1585 \mathrm{~cm}^{-1}$ ). IR spectra obtained in the egg tempera specimens inoculated with Aspergillus niger, Mucor rouxii and Trychoderma pseudokoningii showed lower value for the amide I/amide II intensity ratio. In addition, the amide I band exhibited a decrease of the relative intensity of $\beta$-sheet to $\alpha$-helix sub-bands. In the IR spectra of the two latter specimens this change was accompanied by a splitting of the $\beta$-sheet sub-band in two overlapped components (plateau $1633-1620 \mathrm{~cm}^{-1}$ ) at $1633 \mathrm{~cm}^{-1}$ (intramolecular $\beta$-sheet) and $1620 \mathrm{~cm}^{-1}$ (intermolecular $\beta$-sheet) as it can be seen in the EG@Mr spectrum shown in Fig. 8a. These changes put in evidence the transformation of the protein and polypeptide molecules to more open structures that favour the interaction of the functional groups located in the side chains of the polypeptides with the external medium. More appreciable shoulder of the amide II band at $1585 \mathrm{~cm}^{-1}$ was also observed for these paint films, which indicates that formation of $\mathrm{Cu}$-carboxylate complexes has taken place at significant extent promoted by an increase of the exposition of the protein chain to the external ionomeric layer (vide infra). IR spectrum of the paint film inoculated with Penicillium chrysogenum showed an intermediate behaviour characterized by the decrease of the relative intensity of the $\beta$-sheet to $\alpha$-helix sub-bands and a lesser blueshift of the maximum of the amide I band to $1633 \mathrm{~cm}^{-1}$. Shoulder at $1585 \mathrm{~cm}^{-1}$ in the amide II band was also less evident.

The egg tempera of the two paint film specimens inoculated with the actinobacteria Streptomyces cellulofans and Arthrobacter oxydans exhibited different behaviour. In EG@Sc (see Fig. 8a) maximum of the amide I band was found at $1637 \mathrm{~cm}^{-1}$. This sub-band has been frequently associated to the more open random coil conformation. Secondary maxima at 1648 and $1628 \mathrm{~cm}^{-1}$, which are associated to $\alpha$-helix and $\beta$-sheet conformations, respectively, were also present in this IR spectrum. In contrast, $\beta$-sheet conformation was prevalent in EG@ Ao and thus, this specimen exhibited slight increase in the relative intensity of the $\beta$-sheet to $\alpha$-helix sub-bands relative to the uninoculated film. A blueshift of the prevalent $\beta$-sheet sub-band to $1632 \mathrm{~cm}^{-1}$ together with a new secondary maximum at $1640 \mathrm{~cm}^{-1}$, ascribed to random coils, were the more remarkable features exhibited by the binding medium of the paint film inoculated with the eubacteria Bacillus amyloliquefaciens. The three specimens inoculated with bacteria showed weak shoulder of $\mathrm{Cu}$-carboxylate complexes at $1585 \mathrm{~cm}^{-1}$.

The inoculated egg-oil emulsion paint films, similarly to the uninoculated specimen, exhibited characteristic 

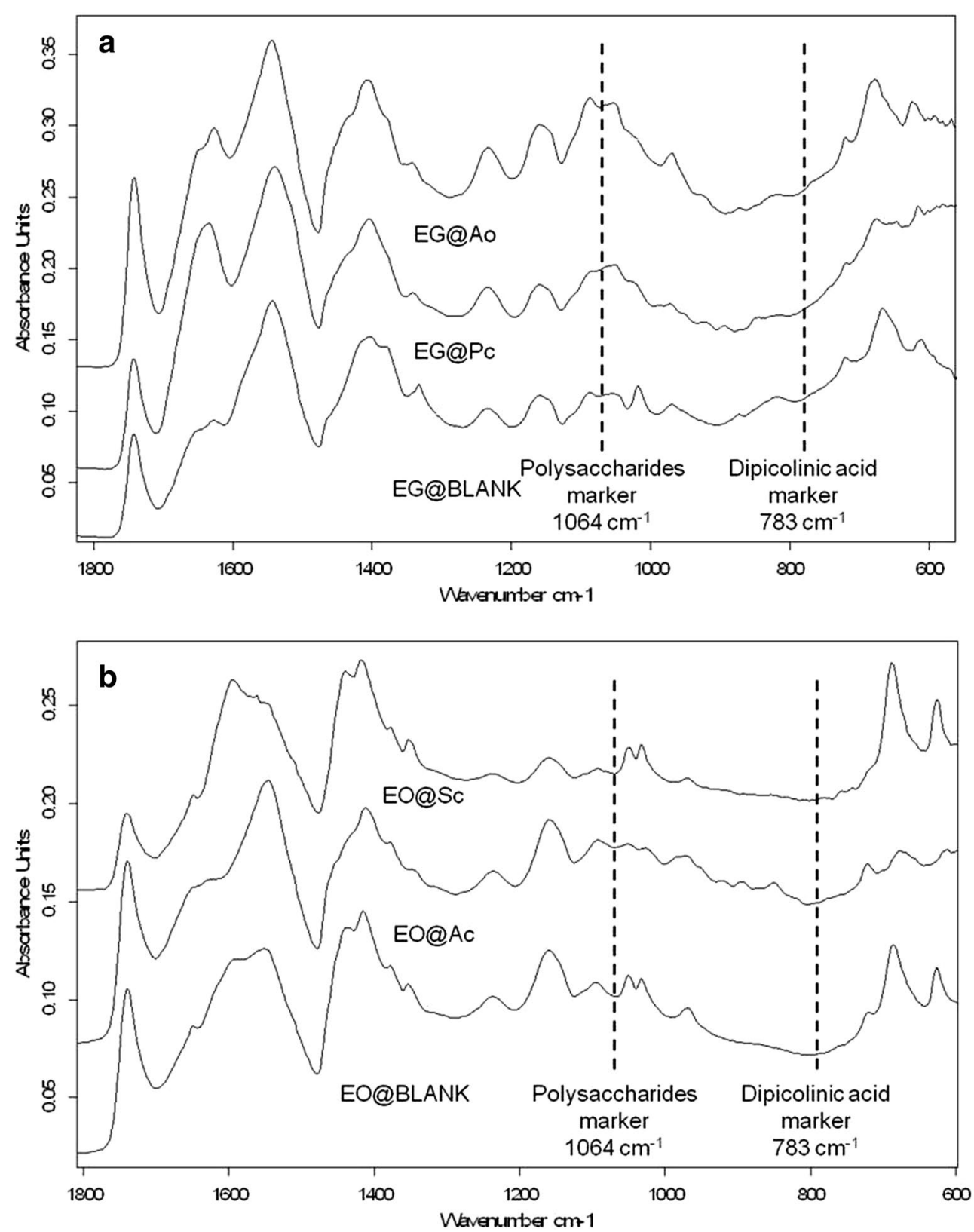

Fig. 7 Detail of the $1800-500 \mathrm{~cm}^{-1}$ IR region and position of the bands characteristic of marker compounds of bacterial and fungal materials: a egg tempera paint film specimens EG@BLANK, EG@Pc and EG@Ao, b egg-oil emulsion paint film specimens EO@BLANK, EO@Ac, and EO@Sc

$\mathrm{C}=\mathrm{O}$ stretching band at $1700-1705 \mathrm{~cm}^{-1}$ ascribed to free fatty acids that denote that hydrolysis of lipids has taken place at some extent. The paint film inoculated with Trychoderma pseudokoningii (see EO@Tp in Fig. 8b) presented a IR spectrum close to that of the blank specimen with maximum of $\alpha$-helix conformation at $1648 \mathrm{~cm}^{-1}$ and $\beta$-sheet sub-band overlapped by the plateau appearing at $1595-1585 \mathrm{~cm}^{-1}$ ascribed to the carboxylate stretching band from verdigris and $\mathrm{Cu}$-carboxylate complexes.
IR spectra obtained in paint films inoculated with Mucor rouxii, Acremonium chrysogenum and Aspergillus niger (see EO@An in Fig. 8b) exhibited discernible maximum of $\beta$-sheet sub-band at $1621 \mathrm{~cm}^{-1}$. Shoulder at $1585 \mathrm{~cm}^{-1}$ ascribed to $\mathrm{Cu}$-carboxylate complexes with fatty acids and amino acids was recognizable in the profile of the amide II band. Amide I band was well-resolved in the IR spectrum of the paint film inoculated with Penicillium chrysogenum with maximum in the $\beta$-sheet region at 

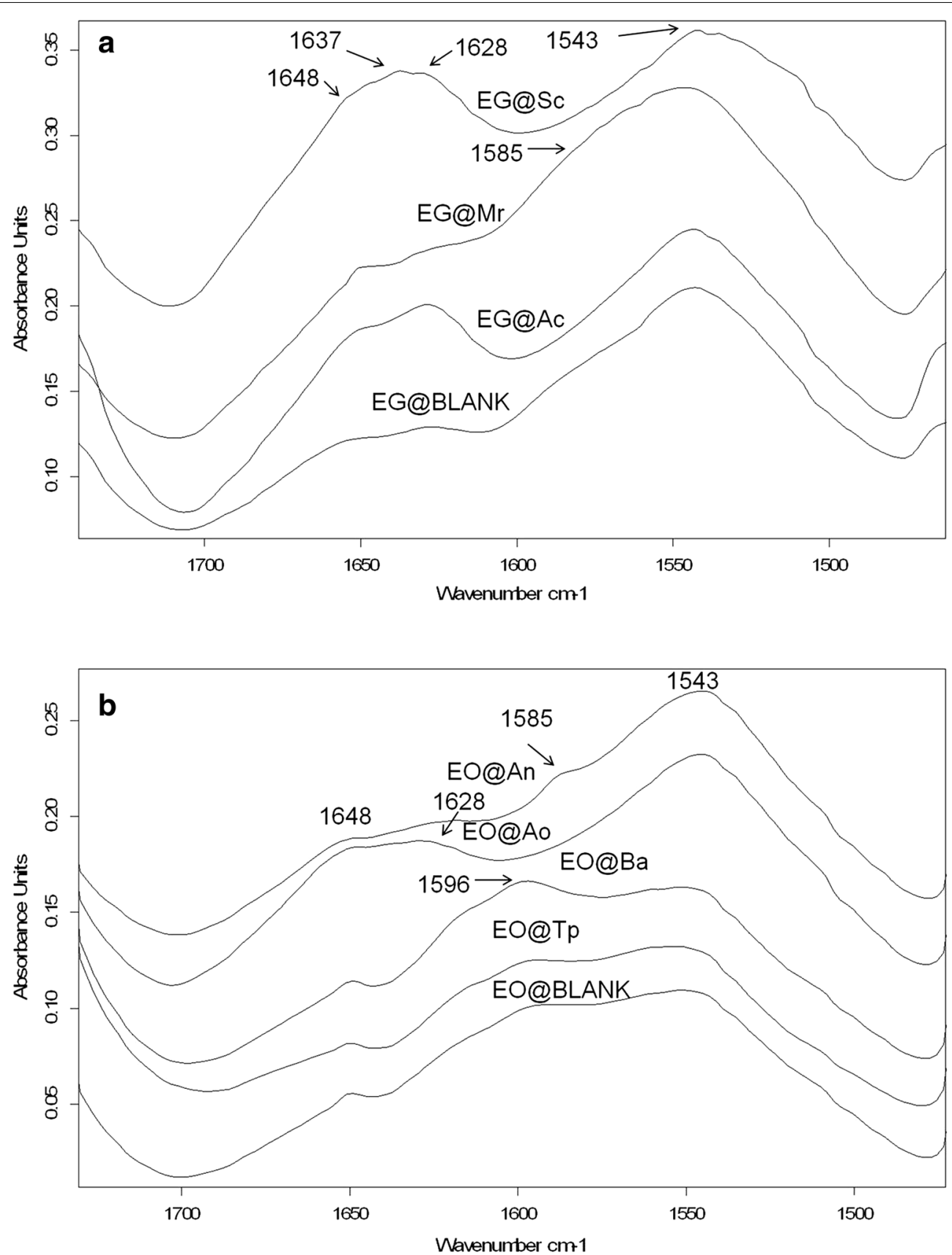

Fig. 8 a IR spectra of inoculated egg tempera paint film specimens EG@BLANK, EG@Sc, EG@Mr, EG@Ac. b IR spectra of inoculated egg-oil emulsion paint film specimens EO@BLANK, EO@An, EO@Tp, EO@Ao and EG@Ba

$1630 \mathrm{~cm}^{-1}$ accompanied with weak features characteristic of $\mathrm{Cu}$-carboxylates.

Similarly to that found for egg tempera specimens, the egg oil emulsion of the two paint film specimens inoculated with the actinobacteria Streptomyces cellulofans and Arthrobacter oxydans exhibited different behaviour. EO@Ao showed a well resolved amide I band with maximum in the $\beta$-sheet region at $1628 \mathrm{~cm}^{-1}$ (see EO@Ao in Fig. 8b) accompanied of $\alpha$-helix secondary maximum at $1648 \mathrm{~cm}^{-1}[44,45]$. Cucarboxylate complexes and verdigris bands were completely overlapped with amide II band. In contrast, EO@Sc showed an IR spectrum quite similar to that of the EO@Ba corresponding to the eubacteria Bacillus amyloliquefaciens and close to that of the uninoculated specimen. 


\section{VMP analysis}

Figure 9 shows the cyclic voltammograms (CVs) of microparticulate deposits of $(a, b)$ verdigris and $(c, d)$ un-inoculated verdigris egg tempera paint film (EO@Vd_ BLANK) attached to graphite bar immersed into aqueous acetate buffer at $\mathrm{pH}$ 4.75. Upon scanning the potential from $0.0 \mathrm{~V}$ vs. $\mathrm{Ag} / \mathrm{AgCl}$ in the negative direction (Fig. 9a), the pigment displays two cathodic peaks at $-0.25\left(\mathrm{C}_{1}\right)$ and $-0.70 \mathrm{~V}\left(\mathrm{C}_{2}\right)$ which are followed, in the subsequent anodic scan, by a series of overlapping tall peaks around $+0.20\left(\mathrm{~A}_{1}\right)$. The peak $\mathrm{C}_{1}$ is clearly larger than the peak $\mathrm{C}_{2}$, as can be seen using square wave voltammetry (SWV, Fig. $9 \mathrm{~b}$ ) and is coupled to the group of signals $A_{1}$, as can be seen in CVs in which the potential is switched after passing the signal $C_{1}$ (see Fig. 10 for un-inoculated verdigris egg-oil emulsion paint film (EG@BLANK)). Since, in the light of abundant literature on copper pigments and corrosion products $[16,17,46]$, the signal $A_{1}$ can unambiguously be attributed to the oxidative dissolution of metallic $\mathrm{Cu}$ formed in prior reductive steps, one can conclude that the process $\mathrm{C}_{1}$ consists of the two-electron reduction of verdigris. This process can be represented as:

$\left\{\mathrm{Cu}(\mathrm{Ac})_{2}\right\}_{\text {solid }}+2 \mathrm{H}_{\mathrm{aq}}^{+}+2 \mathrm{e}^{-} \rightarrow\{\mathrm{Cu}\}_{\text {solid }}+2 \mathrm{HAc}_{\mathrm{aq}}$

The peak splitting appearing in the signal $\mathrm{A}_{1}$ can be attributed to the superposition of the oxidation processes of different deposits of metallic copper, a frequent feature

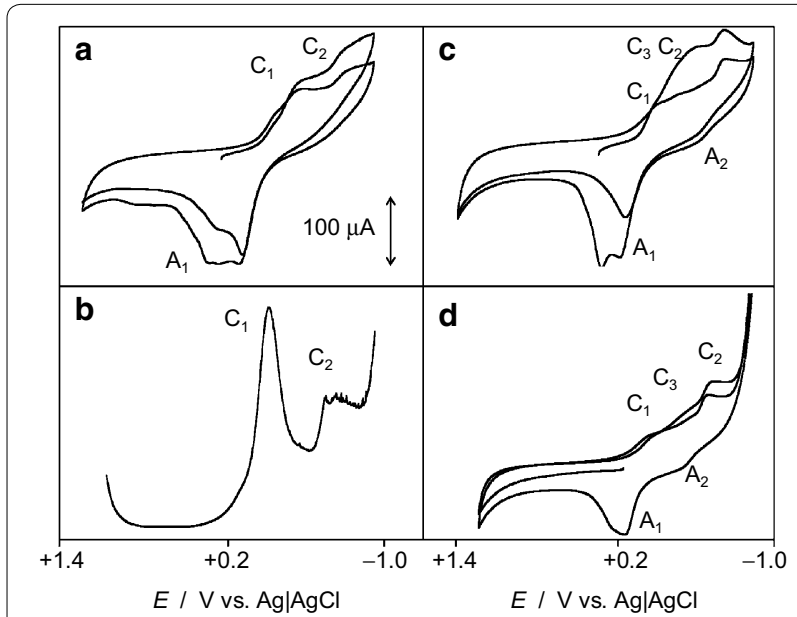

Fig. 9 Voltammetric response of microparticulate deposits of $\mathbf{a}, \mathbf{b}$ verdigris and $\mathbf{c}, \mathbf{d}$ un-inoculated verdigris egg tempera paint film (EG@BLANK) attached to graphite bar immersed into $0.25 \mathrm{M} \mathrm{HAc/}$ NaAc aqueous buffer, pH 4.75. a, c Negative-going CVs, potential scan rate $50 \mathrm{mV} \mathrm{s}^{-1} ;$ b negative-going SWV, potential step increment $4 \mathrm{mV}$, square wave amplitude $25 \mathrm{mV}$, frequency $5 \mathrm{~Hz}$; d positive going $\mathrm{CV}$, potential scan rate $50 \mathrm{mV} \mathrm{s}^{-1}$

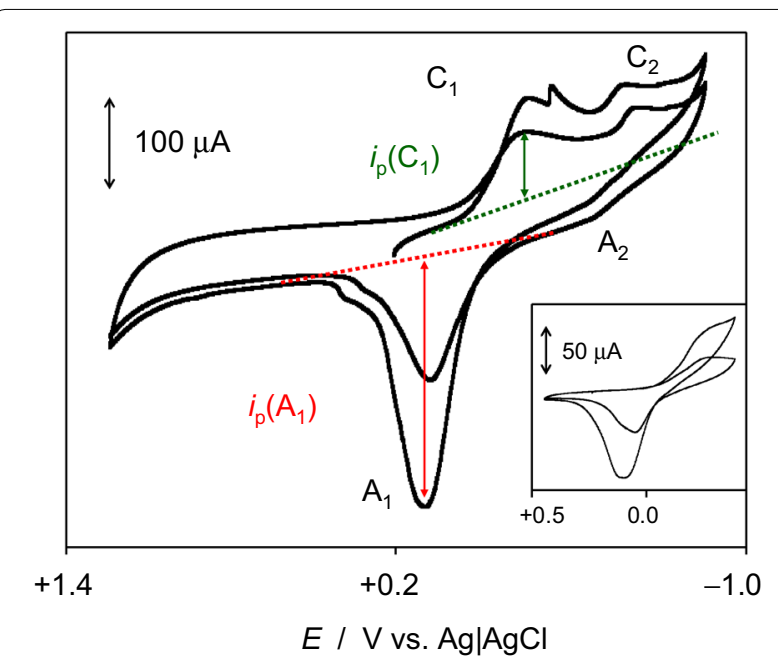

Fig. 10 Cyclic voltammetry of un-inoculated verdigris egg-oil emulsion paint film (EO@ BLANK) attached to graphite bar immersed into $0.25 \mathrm{M} \mathrm{HAc/NaAc}$ aqueous buffer, $\mathrm{pH} 4.75$; potential scan rate $50 \mathrm{mV} \mathrm{s}^{-1}$. Inset voltammogram recorded in the potential range where the $C_{1} / A_{1}$ couple appears. The base lines for measuring peak currents are depicted

in the voltammetry of copper, lead, and mercury minerals [46-49]. The formation of different copper deposits results from the superposition of different reductive process so that the process described by Eq. (1) can proceed via topotactic conversion of copper acetate into $\mathrm{Cu}$, as described for several lead compounds $[50,51]$ but also involving intermediate species in solution [52]. In turn, the cathodic process $\mathrm{C}_{2}$ can be assigned to the reduction of some $\mathrm{Cu}_{\mathrm{aq}}^{2+}$ ions generated during the precedent reductive step $\mathrm{C}_{1}$ at the $\mathrm{Cu}$-plated electrode.

The voltammetric response of un-inoculated verdigris egg tempera paint film (EO@BLANK) exhibited significant variations relative to that of the pure pigment. As can be seen in Fig. 9c, in the initial cathodic scan CVs, the peak $C_{1}$ became lowered relative to the signal $C_{2}$ which was preceded by an additional cathodic signal at ca. $-0.35 \mathrm{~V}\left(\mathrm{C}_{3}\right)$. These features were also recorded in the initial anodic scan CVs (Fig. 9d) where one can see that the group of oxidative signals $\mathrm{A}_{1}$ only appears after the occurrence of the reductive process $\mathrm{C}_{1}$. Interestingly, upon repetitive cycling the potential scan, the cathodic current at ca. $-1.0 \mathrm{~V}$, attributable to proton discharge, was considerably enhanced, a phenomenon which can be due to the catalytic effect exerted by the formation of relatively gross deposits of metallic copper. Another peculiar feature of verdigris containing paint films was the appearance of a weak anodic signal at ca. $-0.45 \mathrm{~V}\left(\mathrm{~A}_{2}\right)$. This signal can be attributed, tentatively, to the oxidation of intermediate $\mathrm{Cu}(\mathrm{I})$ species, stabilized by interaction with the binding media, generated during the cathodic 
process $\mathrm{C}_{2}$. The voltammetry of un-inoculated verdigris egg-oil emulsion paint film (EG@BLANK, Fig. 10) was similar to that of the pure pigment, the peak $C_{3}$ at $-0.35 \mathrm{~V}$ being almost entirely absent, but differing in the presence of peak $A_{2}$ and the absence of important peak splitting in the anodic signal $A_{1}$.

The above voltammetry can be described, as in the case of CdS-based films [18], as resulting from the superposition of different electrochemical process and assuming that the EG and EO reconstructed paint films were constituted by a more or less homogeneous distribution of pigment particles partially embedded by a hydrophobic layer of binder accompanied by a hydrophilic layer where different metal compounds exist, as described for pictorial specimens containing lead pigments [49, 52, 53]. In situ XRD [50] and AFM [51] studies coupled to VMP from Scholz et al., suggested that the reduction of litharge and other metal compounds to metal involved a solid state transformation of lead oxide to lead metal without a morphological disintegration, the advance of the reaction involving the formation of an intermediate layer containing metal atoms, hydroxide ions and water molecules. The peak $\mathrm{C}_{3}$ appearing in EG and EO reconstructed paint films can be attributed to the reduction of $\mathrm{Cu}$ (II) species formed in the ionomeric layer accompanying the pigment particles. This layer, to some extent similar to that formed in the reduction of lead minerals [50-53] would be particularly relevant for the proteinaceous fraction of the binders (egg) disposing of coordinating units [18]. In contrast with CdS-based reconstructed paint films, no drastic differences were found between the voltammetric response of EG and EO specimens before to be submitted to biological attack. Figure 11 depicts a scheme for interpreting the electrochemistry of verdigris-based paint films based on the description of Lovric, Scholz, Oldham and co-workers on the electrochemistry of ion-insertion solids [54-59]. In the studied specimens, the signal $C_{1}$ corresponds to the proton-assisted reduction of the fraction of the pigment grains directly exposed to the electrode so that the redox reaction starts at the particle/base electrode/ electrolyte three-phase junction. This process involves the formation of an ionomeric layer around the pigment grain but also the partial release of 'free' copper ions into the same and/or the surrounding electrolyte solution then undergoing the reduction process $C_{2}$. The process $C_{3}$ can be assigned to the reduction of copper complexes formed in the verdigris grain/binder boundary which presumably forms an ionomeric coverage around the pigment grains (different to that promoted electrochemically in the process $C_{1}$ ) as a result of the coordinating ability of the proteinaceous fraction.

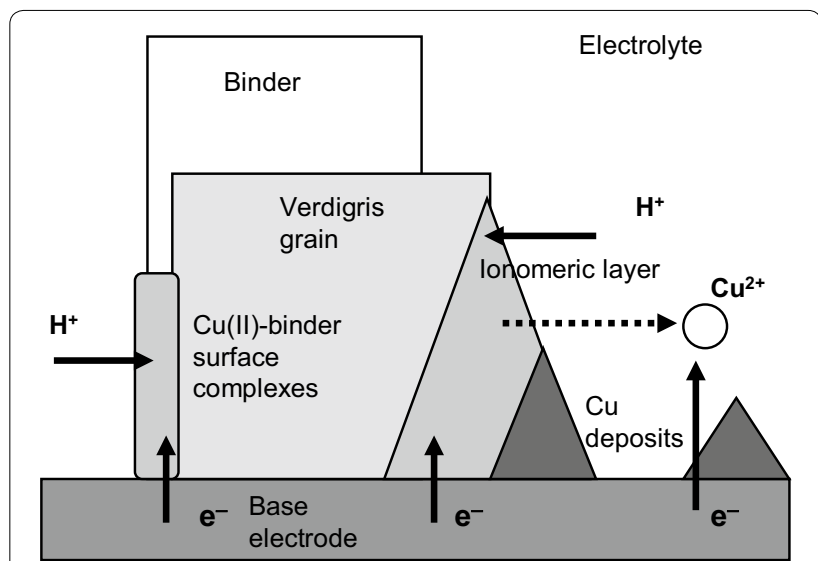

Fig. 11 Scheme for the electrochemical processes involved in the reduction of reconstructed verdigris/binder paint film specimens attached to graphite electrodes in contact with acidic aqueous electrolytes

$$
\begin{aligned}
& \left\{\mathrm{Cu}^{2+}\left(\text { binding }^{2-}\right)\right\}_{\mathrm{Vd} \text { ionomeric layer }} \\
& \quad+2 \mathrm{H}_{\mathrm{aq}}^{+}+2 \mathrm{e}^{-} \rightarrow\{\mathrm{Cu}\}_{\text {solid }}+\mathrm{H}_{2} \text { binding }
\end{aligned}
$$

\section{VMP testing of biodeterioration}

The voltammetric response of the reconstructed model paint films specimens was differently modified after inoculation. The voltammograms obtained for the verdigris egg paint film specimens inoculated with (a, b) Acremonium chrysogenum (EG@Ac) fungi and (c, d) Arthrobacter oxydans (EG@Ao) bacteria are shown in Fig. 12. The most relevant feature was the broadening of both the cathodic and anodic regions of the voltammograms with the appearance of an additional peak at ca. $-0.55 \mathrm{~V}$ $\left(C_{4}\right)$. Peaks $C_{1}-C_{4}$ can be resolved upon semi-derivative deconvolution of the current/potential curves (Fig. 12b, d).

$\mathrm{CVs}$ of graphite electrodes modified with verdigris egg-oil emulsion paint films immersed into $0.25 \mathrm{M}$ sodium acetate buffer, $\mathrm{pH} 4.75$ after incubation with: (a) Mucor rouxii (EO@Mr) and, (b) Acremonium chrysogenum (EO@Ac) fungi and; (c) Streptomyces cellulofans (EO@Sc) and, (d) Arthrobacter oxydans (EO@Ao) bacteria are shown in Fig. 10. Specimens inoculated with fungi (Fig. 13a, b) displayed similar voltammetric features characterized by the engrossment of the $\mathrm{C}_{1}$ peak, being preceded by a shoulder at ca. $-0.12 \mathrm{~V}\left(\mathrm{C}_{5}\right)$, now strongly overlapped with $\mathrm{C}_{3}$ and $\mathrm{C}_{4}$ signals, the lowering of the peak $C_{2}$ and the appearance of two overlapping intense anodic peaks in the $A_{1}$ region of potentials. The most significative changes are observed for the verdigris eggoil emulsion paint films specimens inoculated with bacteria. Figure 13c, d show the voltammograms obtained 


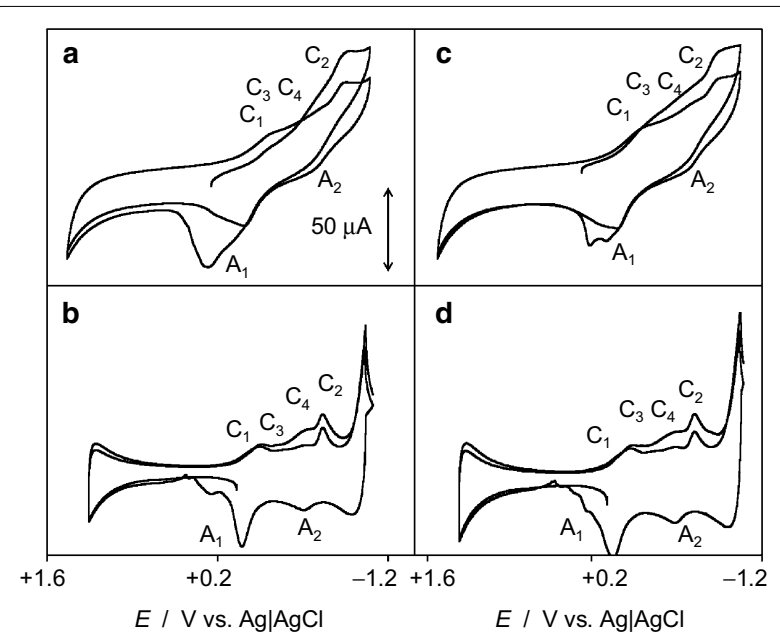

Fig. $12 \mathrm{CV}$ s of graphite electrodes modified with verdigris egg tempera paint films immersed into $0.25 \mathrm{M}$ sodium acetate buffer, $\mathrm{pH} 4.75$, after incubation with: a, b Acremonium chrysogenum (EG@Ac) fungi and $\mathbf{c}, \mathbf{d}$ Arthrobacter oxydans (EG@Ao) bacteria. Voltammograms before $(\mathbf{a}, \mathbf{c})$ and after $(\mathbf{b}, \mathbf{d})$ semi-derivative convolution; potential scan rate $50 \mathrm{mV} \mathrm{s}^{-1}$

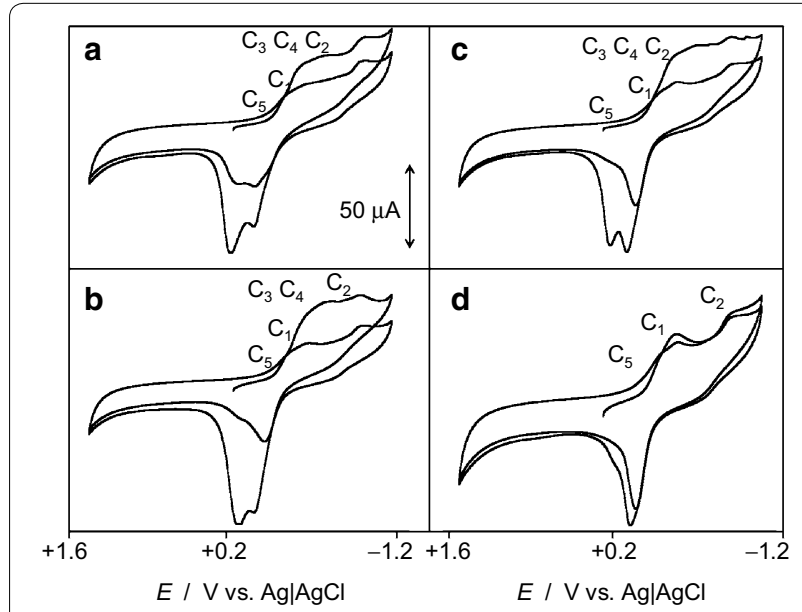

Fig. $13 \mathrm{CV}$ s of graphite electrodes modified with verdigris egg-oil emulsion paint films immersed into $0.25 \mathrm{M}$ sodium acetate buffer, $\mathrm{pH}$ 4.75 after incubation with: a Mucor rouxii (EO@Mr) and, b Acremonium chrysogenum (EO@Ac) fungi and; c Streptomyces cellulofans (EO@Sc) and, $\mathbf{d}$ Arthrobacter oxydans (EO@Ao) bacteria. Potential scan rate $50 \mathrm{mV} \mathrm{s}^{-1}$

for Streptomyces cellulofans and Arthrobacter oxydans which are representative of two apparently extreme behaviors. The $\mathrm{CV}$ of the former was similar to those of specimens inoculated with fungi. In contrast, the specimens inoculated with Arthrobacter oxydans produced a 'clean' voltammogram dominated by peaks $C_{1}$ and $C_{2}$ with no peak splitting in the signal $A_{1}$ in good agreement with the results obtained by FTIR spectroscopy.
The voltammograms for Bacillus amyloliquefaciens, were intermediate between those of Streptomyces cellulofans and Arthrobacter oxydans.

The voltammetric features appearing after biological attack can be attributed to the superposition of two main factors: (i) the degradation of the binder resulting in an increased exposition of the verdigris particles favoring the process $C_{1}$, and (ii) the increase of the ionomeric layer of $\mathrm{Cu}(\mathrm{II})$-binding compounds, thus increasing the intensity of the peak $C_{3}$, promoting the appearance of a new signal $\mathrm{C}_{4}$, and retaining 'free' $\mathrm{Cu}^{2+}$ ions generated in the reductive step $C_{1}$ with the concomitant decrease of peak $\mathrm{C}_{2}$. It is pertinent to note that, under our experimental conditions, the possible voltammetric response of electroactive metabolites in biofilm residuals and their occasional complexes with released copper ions should be considerably weaker than that of pigment-based species.

The observed changes in the voltammetric response of the films upon biodeterioration are in good agreement with the transformations taking place in the secondary structure of proteins observed in the inoculated specimens, in particular, the increase in the random coils (band at $1637 \mathrm{~cm}^{-1}$ ) and $\mathrm{Cu}$-protein complexes (band at $\left.1585 \mathrm{~cm}^{-1}\right)$. The cathodic shoulder $C_{5}$ was characteristic of EO reconstructed paint film. This signal can be attributed to the reduction of $\mathrm{Cu}(\mathrm{II})$ soaps formed upon coordination with the carboxylate units of the oil fraction of the binder and is consistent with the intense IR band at $1585 \mathrm{~cm}^{-1}$ exhibited by the inoculated specimens (see Fig. 8b) corresponding to the asymmetric stretching vibrations of $\mathrm{Cu}(\mathrm{II})$-fatty acid complexes formed in egg-oil emulsion films inoculated with both bacteria and fungi. A similar response was observed for CdS-based films; accordingly, the reduction process $C_{5}$ can be represented as:

$$
\begin{aligned}
& \left\{\mathrm{Cu}^{2+}\left(\mathrm{RCOO}^{-}\right)_{2}\right\}_{\text {Cu soap }} \\
& \quad+2 \mathrm{H}_{\mathrm{aq}}^{+}+2 \mathrm{e}^{-} \rightarrow\{\mathrm{Cu}\}_{\text {solid }}+2 \mathrm{RCOOH}
\end{aligned}
$$

Interestingly, the formation of copper soaps (denoted by the shoulder $\mathrm{C}_{5}$ ) was a common factor for the attack of both fungi and bacteria to EO films, whereas the degradation of the proteinaceous fraction of the binder (denoted by peaks $\mathrm{C}_{3}, \mathrm{C}_{4}$ ) varied significantly from one species to another, being minimal in the case of Arthrobacter oxydans (compare Fig. 12a-c with Fig. 13d). This result is coherent with the IR spectrum obtained in this specimen that exhibited an intense and well-resolved amide I band.

In order to group the observed voltammetric responses, the ratios between the peak currents for the processes $\mathrm{C}_{2}$ and $\mathrm{C}_{1}, i_{\mathrm{p}}\left(\mathrm{C}_{2}\right) / i_{\mathrm{p}}\left(\mathrm{C}_{1}\right)$ and $\mathrm{C}_{3}$ plus $\mathrm{C}_{4}$ and $\mathrm{C}_{1},\left(i_{\mathrm{p}}\left(\mathrm{C}_{3}\right)+i_{\mathrm{p}}\left(\mathrm{C}_{4}\right)\right) / i_{\mathrm{p}}\left(\mathrm{C}_{1}\right)$ were calculated. These ratios 
can be considered as representative, respectively, of the extent of the release of $\mathrm{Cu}^{2+}$ ions, in turn roughly indicative of the accessibility of the verdigris grains to direct electrochemical reduction, and the extent of the biological attack on the proteinaceous fraction of the binder. Figure 14a shows experimental data for the attack of the studied biological agents on EG specimens, using for peak current measurements the base lines depicted in Fig. 10. One can see in this figure that the data points are concentrated in a relatively narrow region of the diagram with the unique exception of Acremonium chrysogenum, thus suggesting a common behavior which could be tentatively fitted to a linear tendency (dotted line).

A similar, unclear situation was obtained in the representation for the ratio between peak currents of the two main components of the anodic signal $\mathrm{A}_{1}, i_{\mathrm{p}}\left(\mathrm{A}_{1}{ }^{\prime}\right) / i_{\mathrm{p}}\left(\mathrm{A}_{1}{ }^{\prime \prime}\right)$ vs. the $\left(i_{\mathrm{p}}\left(\mathrm{C}_{3}\right)+i_{\mathrm{p}}\left(\mathrm{C}_{4}\right)\right) / i_{\mathrm{p}}\left(\mathrm{C}_{1}\right)$ ratio for reconstructed verdigris egg tempera paint films after inoculation with biological species in this study (Fig. 14b). The $i_{\mathrm{p}}\left(\mathrm{A}_{1}{ }^{\prime}\right) / i_{\mathrm{p}}\left(\mathrm{A}_{1}{ }^{\prime \prime}\right)$ ratio can be taken as representative of the fraction of
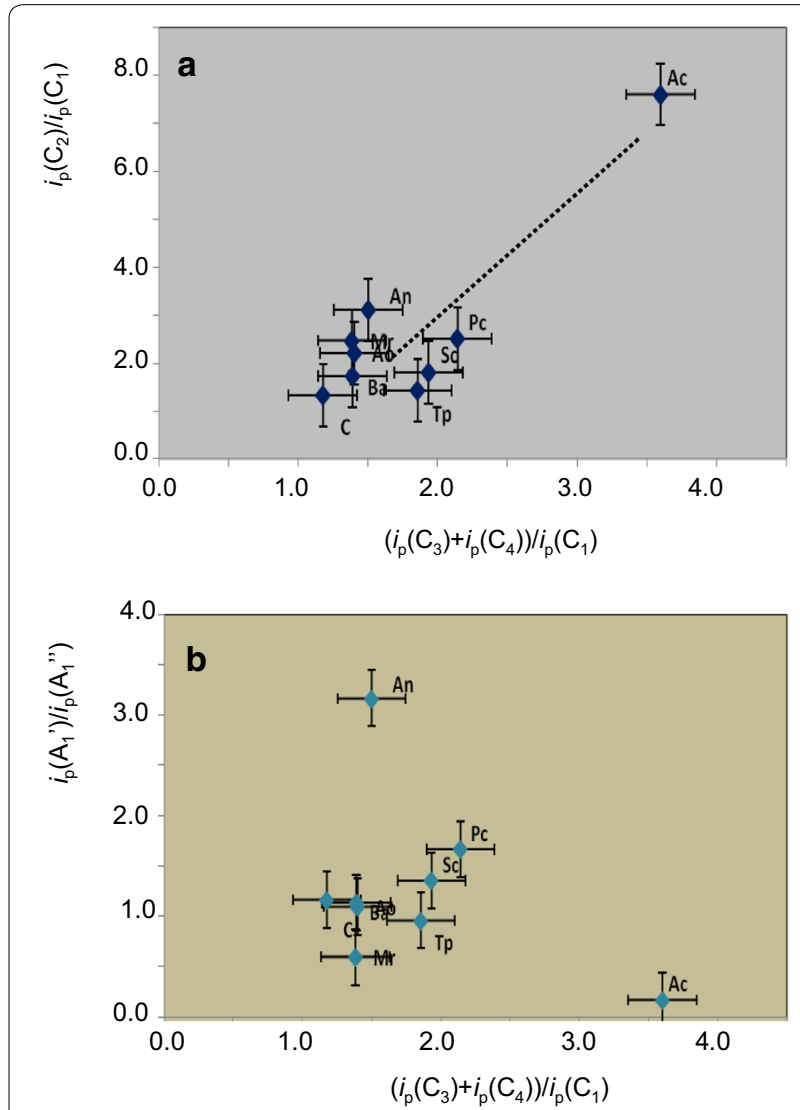

Fig. 14 Plots of: $\mathbf{a} i_{p}\left(C_{2}\right) / i_{p}\left(C_{1}\right)$ vs. $\left(i_{p}\left(C_{3}\right)+i_{p}\left(C_{4}\right)\right) / i_{p}\left(C_{1}\right)$ and $\mathbf{b}$ $i_{\mathrm{p}}\left(\mathrm{A}_{1}{ }^{\prime}\right) / i_{\mathrm{p}}\left(\mathrm{A}_{1}{ }^{\prime \prime}\right)$ vs. $\left(i_{\mathrm{p}}\left(\mathrm{C}_{3}\right)+i_{\mathrm{p}}\left(\mathrm{C}_{4}\right)\right) / i_{\mathrm{p}}\left(\mathrm{C}_{1}\right)$ for reconstructed verdigris egg tempera paint films after inoculation with biological species in this study. From CVs in conditions such as in Fig.4.Ac EG@Ac,AnEG@ An,MrEG@Mr,PcEG@Pc,TpEG@Tp, AoEG@Ao,BaEG@Ba, ScEG@Sc, EG@BLANKC exposed verdigris grains relative to the pigment altered as a result of the biological attack. Although the majority of data points in Fig. 14b are grouped in a relatively small region, Aspergillus niger falls in a clearly separated region (different behaviour was also observed in the IR spectrum of this specimen). These features suggest that there are highly specific behaviors relative to the biological attack. Such differences can be associated to the specificity of the sensibility of the biological agents to the biocide effect due to verdigris. It is known that copper salts act as relatively non-specific bactericide and fungicide [60] the cupric ion being the active species. The mode of action, after absorption into the fungus or bacterium, involves bonding to various chemical groups (imidazoles, phosphates, sulfhydryls, hydroxyls) presented in many proteins and disrupt the function of these proteins and enzymes, resulting cell damage and membrane leakage [61]. According to data in Fig. 14, Acremonium chrysogenum would be highly sensitive to that effect.

In the case of reconstructed verdigris egg-oil emulsion paint films submitted to biodeterioration, the plots of $i_{\mathrm{p}}\left(\mathrm{C}_{2}\right) / i_{\mathrm{p}}\left(\mathrm{C}_{1}\right)$ vs. $\left(i_{\mathrm{p}}\left(\mathrm{C}_{3}\right)+i_{\mathrm{p}}\left(\mathrm{C}_{4}\right)\right) / i_{\mathrm{p}}\left(\mathrm{C}_{1}\right)$ (Fig. 15a) and $i_{\mathrm{p}}\left(\mathrm{A}_{1}{ }^{\prime}\right) / i_{\mathrm{p}}\left(\mathrm{A}_{1}{ }^{\prime \prime}\right)$ vs. $\left(i_{\mathrm{p}}\left(\mathrm{C}_{3}\right)+i_{\mathrm{p}}\left(\mathrm{C}_{4}\right)\right) / i_{\mathrm{p}}\left(\mathrm{C}_{1}\right)$ (Fig. $\left.10 \mathrm{~b}\right)$ provide a grouping of data points consistent with linear dependences between the above pairs of peak current ratios (dotted lines in Fig. 15). Remarkably, in EO specimens, 'anomalous' responses for Acremonium chrysogenum and Aspergillus niger observed in EG specimens were absent, thus suggesting that the presence of the oil binder minimizes the factors influencing the aforementioned 'anomalous' responses. As an explanatory hypothesis, one can assume that the biocide effect exerted by verdigris would require the release and migration of $\mathrm{Cu}^{2+}$ ions from the pigment grains towards the biological agents. As far as the second phenomenon should be made difficult through the highly hydrophobic oil fraction, the fungi and/or bacteria would be protected from the biocide species and then the specific differences in resistance would be minimized. Consistently with this hypothesis, the height of the peak $\mathrm{C}_{2}$ relative to the peak $\mathrm{C}_{1}$ was larger in EG specimens than in EO specimens submitted to the same biological agent (compare Figs. 9a, 10b for EG@ Ac and EO@Ac), respectively.

In these circumstances, the attack of both fungi and bacteria was apparently similar in verdigris-based paint films, a feature in contrast with the behavior of CdSbased EG and EO paint films, where bacteria attack was concentrated on the most abundant oil fraction of the binding medium and fungi attack was concentrated on the proteinaceous fraction [18]. In view of the recognized antifungal effect of cadmium compounds [61-64], a possible explanation for the differences in the biological attack associated to the different pigments would be, in 

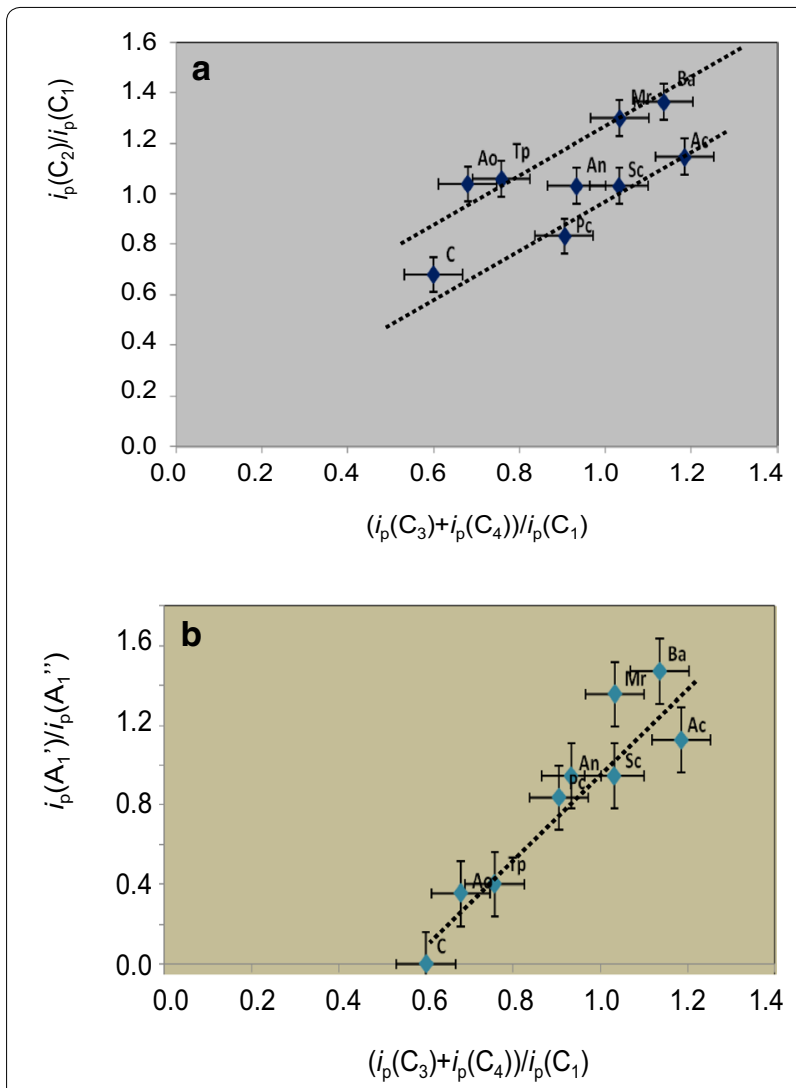

Fig. 15 Plots of: $\mathbf{a} i_{p}\left(C_{2}\right) / i_{p}\left(C_{1}\right)$ vs. $\left(i_{p}\left(C_{3}\right)+i_{p}\left(C_{4}\right)\right) / i_{p}\left(C_{1}\right)$ and $\mathbf{b}$ $i_{p}\left(A_{1}{ }^{\prime}\right) / i_{p}\left(A_{1}{ }^{\prime \prime}\right)$ vs. $\left(i_{p}\left(C_{3}\right)+i_{p}\left(C_{4}\right)\right) / i_{p}\left(C_{1}\right)$ for reconstructed verdigris egg-oil emulsion after inoculation with biological species in this study. From CVs in conditions such as in Fig. 5.Ac EO@Ac, AnEO@An, MrEO@Mr,PcEO@Pc,TpEO@Tp, Ao EO@Ao,BaEO@Ba, ScEO@Sc, EO@BLANKC

line with the foregoing set of considerations, the possible lower release of $\mathrm{Cd}^{2+}$ ions from $\mathrm{CdS}$ relative to the release of $\mathrm{Cu}^{2+}$ ions from verdigris, the different transport ability of such ions in egg and egg-linseed oil films [65], and the possible major specificity of the $\mathrm{Cd}^{2+}$ toxic effects relative to those of $\mathrm{Cu}^{2+}$, these last recognized as highly unspecific [61-64, 66]. For our purposes, the relevant point to emphasize is that the biodegradation of paintings can be notably influenced in both the extent and the specificity of the biological attack by the nature of the pigment.

\section{Conclusions}

The application of the voltammetry of microparticles (VMP) methodology leads to obtain characteristic voltammetric features for verdigris pigment in pictorial specimens combining verdigris and cadmium yellow with egg and egg-linseed oil binders by Penicillium chrysogenum, Aspergillus niger, Acremonium chrysogenum, Trychoderma pseudokoningi and Mucor rouxii fungi and
Bacillus amyloliquefaciens, Arthrobacter oxydans and Streptomyces cellulofans. In contact with aqueous acetate buffer, VMP data denote that in presence of the binder, the voltammetric signals for verdigris in egg and egglinseed oil binders become modified with appearance of specific signals resulting from the pigment-binder association. Depending on the binder; such signals become more or less modified after biodeterioration.

VMP data, supported by ATR-FTIR and FESEM data, suggest that the attack of fungi and bacteria on reconstructed paint films produces significant modifications in the secondary structure of proteins accompanied by release of $\mathrm{Cu}(\mathrm{II})$ ions, the latter enabling the formation of coordination species with carboxylic groups in the side chains of the protein molecules and released fatty acids which results in specific voltammetric features.

Voltammetric data indicate that there is no generic differences in the attack exerted by fungi and bacteria on reconstructed verdigris egg-linseed oil emulsion paint films whereas in the case of reconstructed egg paint films some individual species produced high (Aspergillus niger) and low (Acremonium chrysogenum) deterioration. These peculiar behaviors can be tentatively attributed to the combination of two factors: (i) the existence of individual high/low resistances to the biocide effect of the pigment, and (ii) the hydrophobicity of the oil fraction which made difficult the migration of $\mathrm{Cu}^{2+}$ ions presumably responsible for the biocide effect.

These results support the idea that biodeterioration of pictorial specimens is significantly sensitive to the nature of the pigment and can be electrochemically monitored using solid-state methodologies, as the proposed methodology of potential application for the micro-biological attack characterization.

\section{Authors' contributions}

AOM participated in the research design, prepared pictorial specimens and performed voltammetric analysis; ADC participated in the design and coordination of the study and modeled electrochemical data; MTDC participated in the design and coordination of the study and interpreted infrared and SEM data; LOC performed SEM and FTIR analysis and participated in data interpretation; FBG participated in the design and planning of the biodeterioration experiments; IMS prepared bacteria and fungi stains and performed inoculations. All authors read and approved the final manuscript.

\section{Author details}

${ }^{1}$ Institut de Restauració del Patrimoni, Universitat Politècnica de València, Camí de Vera 14, 46022 Valencia, Spain. ${ }^{2}$ Departament de Química Analítica, Universitat de València, Dr. Moliner, 50, Burjassot, 46100 Valencia, Spain. ${ }^{3}$ Departamento de Pintura, Universidad de Granada, Granada, Spain. ${ }^{4}$ Departamento de Microbiología, Universidad de Granada, Granada, Spain.

\section{Acknowledgements}

This work as been performed by members of the microcluster Grupo de análisis científico de bienes culturales y patrimoniales y estudios de ciencia de la conservación (Ref. 1362) belonging to the Valencia International Campus of Excellence. Financial support is gratefully acknowledged from the Spanish "I+D+I MINECO" projects CTQ2014-53736-C3-1-P and CTQ2014-53736-C3-2-P supported by ERDF funds. 


\section{Competing interests}

All authors declare that they have no competing interests.

Received: 6 October 2016 Accepted: 2 February 2017

Published online: 27 February 2017

\section{References}

1. Matteini M, Moles A. La Chimica nel Restauro. Firenze: Nardini; 1989.

2. Mills JS, White R. The organic chemistry of museum objects. London: Buttersworth; 1994

3. Breitbach AM, Rocha JC, Gaylarde CC. Influence of pigment on biodeterioration of acrylic paint films in Southern Brazil. J Coat Technol Res. 2011:8:619-28

4. Meilunas RJ, Bentsen JG, Steinberg A. Analysis of aged paint binders by FTIR Spectroscopy. Stud Conserv. 1990;35:33-51.

5. Mallégol J, Lemaire J, Gardette JL. Drier influence on the curing of linseed oil. Progr Org Coat. 2009;39:107-13.

6. Erhardt D, Tumosa CS, Mecklenburg MF. Long-term chemical and physical processes in oil paint films. Stud Conserv. 2005;50:143-50.

7. Keune K, van Loon A, Boon JJ. SEM backscattered-electron images of paint cross sections as information source for the presence of the lead white pigment and lead-related degradation and migration phenomena in oil paintings. Micros Microanal. 2011. doi:10.1017/S1431927610094444.

8. Plater MJ, De Silva B, Gelbrich T, Hursthouse MB, Higgitt CL, Saunders DR. The characterization of lead fatty acid soaps in "protusions" in aged traditional oil paint". Polyhedron. 2003;22:3171-9.

9. Robinet L, Corbeil MC. The characterization of metal soaps. Stud Conserv. 2003;48:23-40.

10. Mazzeo R, Prati S, Quaranta M, Joseph E, Kendix E, Galeotti M. Attenuated total reflection micro FTIR characterization of pigment-binder interaction in reconstructed paint films. Anal Bioanal Chem. 2008;392:65-76.

11. Salvadó N, Butí S, Nicholson J, Emerich H, Labrador A, Pradell T. Identification of reaction compounds in micrometric layers from gothic paintings using combined SR-XRD and SR-FTIR. Talanta. 2009;79:419-28.

12. Genestar C, Pons C. Earth pigments in painting: characterization and differentiation by means FTIR spectroscopy. Anal Bioanal Chem 2005;382:269-74

13. Scholz F, Meyer B. Voltammetry of solid microparticles immobilized on electrode surfaces. Electroanal Chem. 1998;20:1-86.

14. Scholz F, Schröder U, Gulabowski R, Doménech-Carbó A. Electrochemistry of Immobilized Particles and Droplets, 2nd edit. Berlin-Heidelberg: Springer; 2014.

15. Doménech-Carbó A, Labuda J, Scholz F. Electroanalytical chemistry for the analysis of solids: characterization and classification (IUPAC Technica Report). Pure Appl Chem. 2013;85:609-31.

16. Doménech-Carbó A, Doménech-Carbó MT, Costa V. Electrochemical methods for archaeometry, conservation and restoration (Monographs in Electrochemistry Series Scholz F Edit). Berlin-Heidelberg: Springer; 2009.

17. Doménech-Carbó A. Electrochemistry for conservation science. J Solid State Electrochem. 2010;14:349-51.

18. Ortiz-Miranda AS, Doménech-Carbó A, Doménech-Carbó MT, OseteCortina L, Bolívar-Galiano FF, Martín-Sánchez I, López-Miras MM. Electrochemical characterization of biodeterioration of paint films containing cadmium yellow pigment. J Solid State Electrochem. 2016;20:3287-302.

19. Kühn $\mathrm{H}$. Verdigris and copper resinate, in artists' pigments. In: Roy A editor. A handbook of their history and characteristics, vol. 2. Oxford: University Press; 1993.

20. Bilardi CR. The red church or the art of Pennsylvania German Braucherei. Los Angeles: Pendraig Publications; 2009.

21. Doménech-Carbó A, Doménech-Carbó MT, Moya-Moreno M, GimenoAdelantado JV, Bosch-Reig F. Identification of inorganic pigments from paintings and polychromed sculptures immobilized into polymer film electrodes by stripping differential pulse voltammetry. Anal Chim Acta. 2000:407:275-89.

22. Ciferri O. Microbial degradation of paintings Appl. Environ Microbiol. 1999;65:879-85

23. Giacobini C, Firpi M. Problemi di microbiologia nei dipinti su tela Opificio delle Pietre Dure e Laboratorio di Restauro di Firenze. Atti del
Convenzione sul Restauro delle Opere d'Arte. Florence: Edizioni Polistampa; 1981. p. 203-11.

24. Giacobini C, De Cicco MA, Tiglie I, Accardo G. Actinomycetes and biodeterioration in the field of fine art. In: Houghton DR, Smith RN, Eggins HOW, editors. biodeterioration, vol. 7. New York: Elsevier; 1988. p. 418-23.

25. Giacobini C, Pedica M, Spinucci M. 31 Problems and future projects on the study of biodeterioration: mural and canvas paintings. In: Proceedings of the 1st international conference on the biodeterioration of cultural property. New Delhi: Macmillan India; 1991. p. 275-286.

26. Ross RT. Microbiology of paint films. Adv Appl Microbiol. 1963;5:217-34

27. Seves AM, Sora S, Ciferri O. The microbial colonization of oil paintings. A laboratory investigation. Int Biodeter Biodegr. 1996;37:215-24.

28. Strelczyc A. Paintings and sculptures. In: Rose AH, editor. Microbialdeterioration. London: Academic; 1981. p. 203-34.

29. Walsh JH. Ecological considerations of biodeterioration. Int. Biodeter. Biodegr. 2001;48:16-25

30. Zyska BJ. Problems of microbial deterioration of materials in Eastern Europe. Int Biodeter Biodegr. 2002;49:73-83.

31. Khandekar N, Phenix A. Some observations on the effects of a selection of pigments on artificially aged egg tempera paint film. Los Angeles: Typescript, GCI Museum Research Laboratory; 1999.

32. Ducce C, Bramanti E, Ghezzi L, Bernazzani L, Bonaduce I, Colombini MP, Sepi A, Biagi S, Tine MR. Interactions between inorganic pigments and proteinaceous binders in reference paint reconstructions. Dalton Trans. 2013:42:5945-84 (and references therein)

33. Miyazawa T, Blout ER. The infrared spectra of polypeptides in various conformations: amide I and II bands. J Am Chem Soc. 1961:83:712-9.

34. Nevskaya YN, Chirgadze NA. Infrared spectra and resonance interaction of amide-I vibration of the antiparallel-chain pleated sheet. Biopolymers. 1976;15:637-48.

35. Qing H, Yanlin H, Fenlin S, Zuyi T. Effects of pH and metal ions on the conformation of bovine serum albumin in aqueous solution. An attenuated total reflection (ATR) FTIR spectroscopic study. Spectrochim Acta A. 1996;52:1795-800

36. Nara M, Morii H, Tanokura M. Coordination to divalent cations by calciumbinding proteins studied by FTIR spectroscopy. Biochim Biophys Acta. 2013;1828:2319-27.

37. Williams RJP. Copper-protein compounds in: the chemistry of the copper and zinc triads. Welch AJ, Chapman K, eds. Royal Society of Chemistry: Cambridge; 1993.

38. Williams RJP, da Silva Frausto JJR. The natural selection of the chemical elements. Oxford: Oxford Univ. Press; 1996.

39. Guthrie RE, Laurie SH. The binding of copper (II) to mohair keratin. Aust J Chem. 1968:21:2437-43.

40. Marey L, Signolle JP, Amiel C, Travert J. Discrimination, classification, identification of microorganisms using FTIR spectroscopy and chemometrics. Vib Spectrosc. 2001;26:151-9.

41. Zotti M, Ferroni A, Calvini P. Mycological and FTIR analysis of biotic foxing on paper substrates. Int Biodeter Biodegr. 2011;65:569-78.

42. Bombalska A, Mularczyk-Oliwa M, Kwásny M, Włodarski M, Kaliszewski M, Kopczynski K, Szpakowska M, Trafny EA. Classification of the biological material with use of FTIR spectroscopy and statistical analysis. Spectrochim Acta A. 2011:78:1221-6.

43. Goodacre R, Shann B, Gilbert RJ, Timmins EM, McGovern AC, Alsberg BK, Kell DB, Logan NA. Detection of the dipicolinic acid biomarker in Bacillus spores using curie-point pyrolysis mass spectrometry and fourier transform infrared spectroscopy. Anal Chem. 2000;72:119-27.

44. Kong J, Yu S. Fourier Transform infrared spectroscopic analysis of protein secondary structures. Acta Biochim Biophys Sinica. 2007;39:549-59.

45. Byler DM, Susi H. Examination of the secondary structure of proteins by deconvolved FTIR spectra. Biopolymers. 1986;25:469-87.

46. Doménech-Carbó A, Doménech-Carbó MT, Valle-Algarra FM, GimenoAdelantado JV, Osete-Cortina L, Bosch-Reig F. On-line database of voltammetric data of immobilized particles for identifying pigments and minerals in archaeometry, conservation and restoration (ELCHER database). Anal Chim Acta. 2016:927:1-12.

47. Zakharchuk N, Meyer S, Lange B, Scholz F. A comparative study of lead oxide modified graphite paste electrodes and solid graphite electrodes with mechanically immobilized lead oxides. Croat Chem Acta. 2000;73:667-704 
48. Komorsky-Lovric S, Lovric M, Bond AM. Comparison of the square-wave stripping voltammetry of lead and mercury following their electrochemical or abrasive deposition onto a paraffin impregnated graphite electrode. Anal Chim Acta. 1992;258:299-305.

49. Arjmand F, Adriaens A. Electrochemical quantification of copper-based alloys using voltammetry of microparticles: optimization of the experimental conditions. J Solid State Electrochem. 2012;16:535-43.

50. Meyer B, Ziemer B, Scholz F. In situ X-ray diffraction study of the electrochemical reduction of tetragonal lead oxide and orthorhombic $\mathrm{Pb}(\mathrm{OH}) \mathrm{Cl}$ mechanically immobilized on a graphite electrode. J Electroanal Chem. 1995;392:79-83.

51. Hasse U, Scholz F. In situ atomic force microscopy of the reduction of lead oxide nanocrystals immobilised on an electrode surface. Electrochem Commun. 2001;3:429-34

52. Doménech-Carbó A, Doménech-Carbó MT, Mas-Barberá X. Identification of lead pigments in nanosamples from ancient paintings and polychromed sculptures using voltammetry of nanoparticles/atomic force microscopy. Talanta. 2007;71:1569-79.

53. Doménech-Carbó A, Doménech-Carbó MT, Mas X, Ciarrocci J. Simultaneous identification of lead pigments and binding media in paint samples using voltammetry of microparticles. Arché. 2007;2:121-4.

54. Jaworski A, Stojek Z, Scholz F. A comparison of simulated and experimental abrasive stripping voltammetric curves of ionic crystals: reversible case. J Electroanal Chem. 1993;354:1-9.

55. Lovric M, Scholz F. A model for the propagation of a redox reaction thorough microcrystals. J Solid State Electrochem. 1997;1:108-13.

56. Lovric M, Hermes M, Scholz F. The effect of the electrolyte concentration in the solution on the voltammetric response of insertion electrodes. J Solid State Electrochem. 1998;2:401-4.

57. Oldham KB. Voltammetry at a three-phase junction. J Solid State Electrochem. 1998;2:367-77

58. Lovric M, Scholz F. A model for the coupled transport of ions and electrons in redox conductive microcrystals. J Solid State Electrochem. 1999:3:172-5.
59. Schröder U, Oldham KB, Myland JC, Mahon PJ, Scholz F. Modelling of solid state voltammetry of immobilized microcrystals assuming an initiation of the electrochemical reaction at a three-phase junction. J Solid State Electrochem. 2000;4:314-24.

60. Reregistration Eligibility Decision (RED) for Coppers. U.S. Environmental Protection Agency, Office of Prevention, Pesticides and Toxic Substances, Office of Pesticide Programs. Washington, DC: U.S. Government Printing Office; 2009.

61. Mirkovic B, Tanovic B, Hrustic J, Mihajlovic M, Stevic M, Delibasic G, Vuksa P. Toxicity of copper hydroxide, dithianon, fluazinam, tebuconazole and pyraclostrobin to Didymella applanata isolates from Serbia. J Environ Sci Health B. 2015;50:175-83.

62. Biswas FB, Roy TG, Rahman MA, Emran TB. An in vitro antibacterial and antifungal effects of cadmium(II) complexes of hexamethyltetraazacyclotetradecadiene and isomers of its saturated analogue. Asian Pac J Trop Med. 2014;7(S1):S534-9.

63. Montazerozohori M, Zahedi S, Nasr-Esfahani M, Naghiha A. Some new cadmium complexes: antibacterial/antifungal activity and thermal behavior. J Ind Eng Chem. 2014;20:2463-70.

64. Montazerozohori M, Musari SA, Masoudiasl A, Naghiga A, Dusek M, Kycerakova M. Synthesis, spectral, crystal structure, thermal behavior, antimicrobial and DNA cleavage potential of two octahedral cadmium complexes: a supramolecular structure. Spectrochim Acta A. 2015;137:389-96.

65. Novakova K, Navratil T, Sestakova I, Lee MP, Vodickova H, Zamecnikova B, Sokolova R, Bulickova J, Gal M. Characterization of cadmium ion transport across model and real biomembranes and indication of induced damage of plant tissues. Monatsch Chem Chem Mont. 2015;146:819-29.

66. Negm NA, Said MM, Morsey SM. Pyrazole derived cationic surfactants and their tin and copper complexes: synthesis activity, antibacterial and antifungal efficacy. J Surfact Deterg. 2010;13:521-8.

\section{Submit your manuscript to a SpringerOpen ${ }^{\circ}$ journal and benefit from:}

- Convenient online submission

- Rigorous peer review

- Immediate publication on acceptance

- Open access: articles freely available online

- High visibility within the field

- Retaining the copyright to your article 